\title{
CONNECTED AND AUTOMATED TRANSPORT IN THE LONG LEVEL 4
}

SETTLEMENT DEVELOPMENT, TRANSPORT POLIGY AND PLANNING DURING THE TRANSITION PERIOD 
4.1

\section{TECHNOLOGICAL DEVELOPMENTS IN CONNECTED AND AUTOMATED VEHICLES: WHAT IS THE STATUS QUO?}

Figure 4.1.1: A LIDAR sensor on the roof of the test vehicle "Homer"

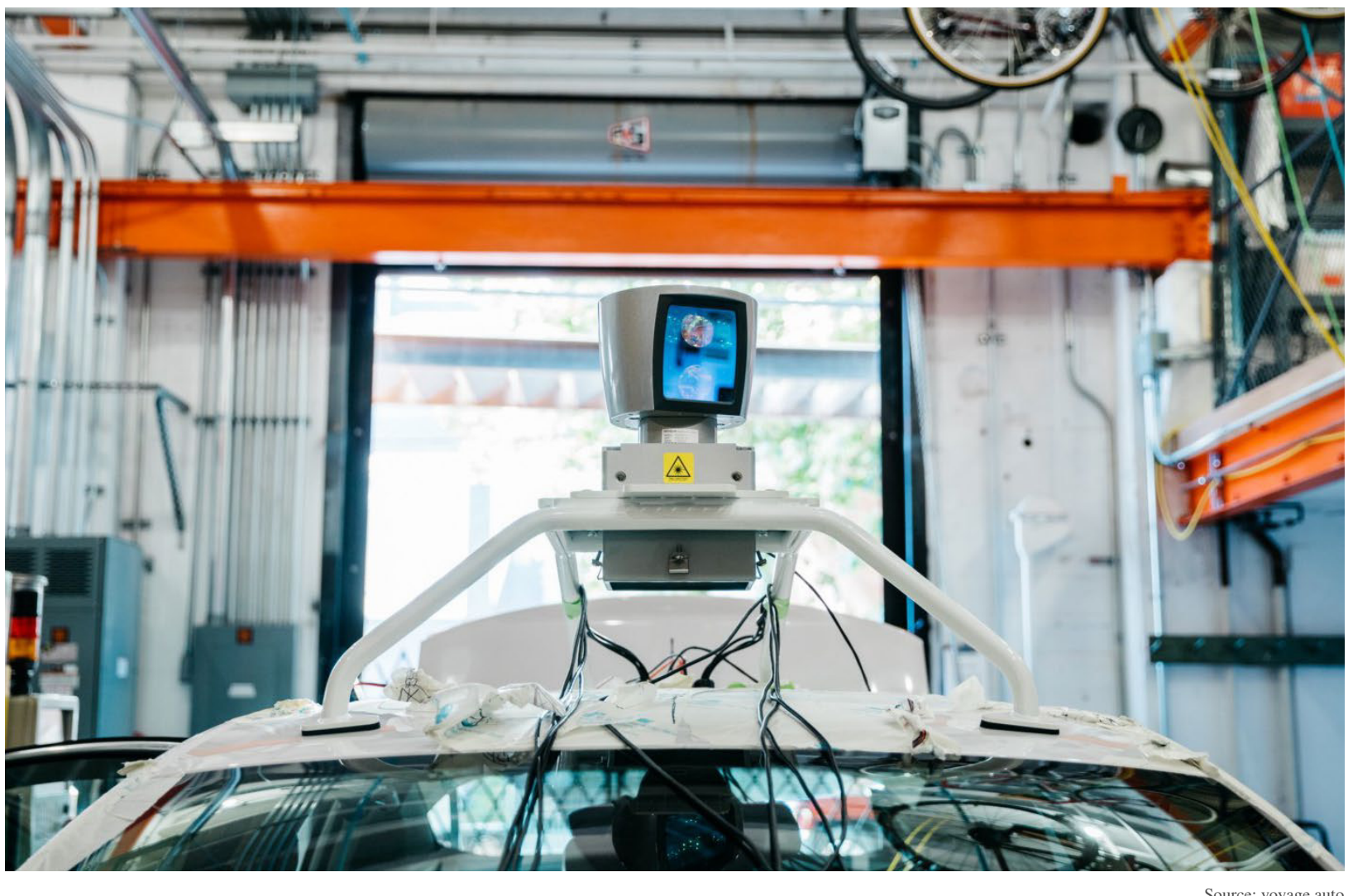

Connection and automation are the instrumental drivers of change in the transport system - yet they are two fundamentally different trends that are not necessarily related to one another (Perret et al. 2017: 6). Despite this, there is growing emphasis on their simultaneity and parallel development: whereas early research frequently spoke of autonomous driving or autonomous vehicles, more recent articles increasingly use the term "connected and automated vehicles": "Even though automated vehicles do not necessarily need to be connected and connected vehicles do not require automation, it is expected that in the medium term connectivity will be a major enabler for automated vehicles" (European Commission 2018: 4).

In response to the array of terms being used and their unclear meanings, SAE International (2018: 28) advises against the terms "self-driving vehicle", "autonomous vehicle" and "driving robot". What is commonly known as a "self-driving" or "autonomous" vehicle corresponds to the "fully automated vehicle" that is recommended in the SAE terminology and thus used here throughout.
The simultaneity of vehicles' connection and automation is explained by the fact that even at this stage increasing connection is seen as a prerequisite for some driving tasks. For instance, details about the current traffic situation, the condition of the roadway and possibly information from the infrastructure itself (traffic lights, tollbooths, etc.) may be necessary to facilitate safe automated operation of the vehicle (Ritz 2018: 184). Furthermore, some of the desired impacts of automated vehicles will only take hold when they act or cooperate in a connected way. Examples include the increased efficiency on roads and in the road network as a result of distribution, raising the vehicle flow rate and improving security (Kagermann 2017: 363; Shladover 2018: 196). That this view is held by the European Commission is evidenced by diverse initiatives and funding programmes (CAM, C-ITS, C-Roads; European Commission 2018: 4).

In addition, this means that although the majority of the first automated driving systems available, which only offer lower-level automated driving functions, are still 
relatively independent and not or hardly connected, it will be important in the long run - when higher levels of automation are achieved - for automated driving systems to be as connected as possible so that the desired effects are indeed achieved (Fig. 4.1.2; Shladover 2018: 193).

Figure 4.1.2: Schematic diagram of the difference between ego-only, cooperative and automated systems

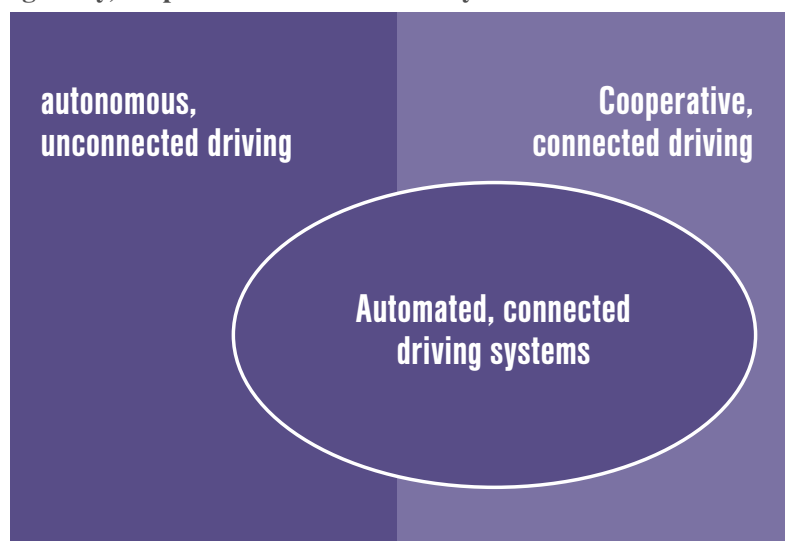

Source: AVENUE21 after Shladover (2018)

\section{AUTOMATION LEVELS AND THEIR MEANINGS}

Vehicles of different sizes are generally considered to be automated once they can perform a large proportion of dynamic driving tasks autonomously; the range of tasks undertaken culminates in fully driverless operation (Fig. 4.1.3). There are different automation level classifications for vehicles in passenger and freight transport, with the J3016 classification by SAE (Society of Automotive Engineers) having become established in the international scientific debate.

Those systems that the driver no longer has to supervise at all times because the longitudinal and lateral vehicle motion control is performed automatically in specific application cases (road types, speed zones and conditions) are known as conditional driving automation. However, the driver potentially has to be capable of taking over if the system requests them to intervene (Level 3). Highly automated vehicles, which are the subject of this research, are those whose systems can deal with

Figure 4.1.3: Stages of automating driving systems

\begin{tabular}{|c|c|c|c|c|c|c|}
\hline LEVEL & NAME & DESCRIPTION & $\begin{array}{l}\text { VEHICLE MO- } \\
\text { TION CONTROL }\end{array}$ & $\begin{array}{l}\text { AWARENESS } \\
\text { OF SURROUND- } \\
\text { INGS }\end{array}$ & $\begin{array}{l}\text { FALLBACK } \\
\text { LEVEL }\end{array}$ & $\begin{array}{l}\text { OPERATIONAL } \\
\text { DESIGN DOMAIN }\end{array}$ \\
\hline \multicolumn{7}{|c|}{ DRIVER PERFORMS ALL DYNAMIC DRIVING TASKS } \\
\hline 0 & $\begin{array}{c}\text { NO } \\
\text { AUTOMATION }\end{array}$ & $\begin{array}{l}\text { Driver drives independently, } \\
\text { even if supporting systems are } \\
\text { available. }\end{array}$ & DRIVER & DRIVER & NONE & $N / A$ \\
\hline 1 & $\begin{array}{l}\text { ASSISTANCE } \\
\text { SYSTEMS }\end{array}$ & $\begin{array}{l}\text { Driver assistance systems help } \\
\text { with operation of the vehicle } \\
\text { during longitudinal or lateral } \\
\text { vehicle motion control (not } \\
\text { simultaneous). }\end{array}$ & $\begin{array}{l}\text { DRIVER AND } \\
\text { SYSTEM }\end{array}$ & DRIVER & DRIVER & LIMITED \\
\hline 2 & $\begin{array}{c}\text { PARTIAL } \\
\text { AUTOMATION }\end{array}$ & $\begin{array}{l}\text { One or more driver assistance } \\
\text { systems help with operation } \\
\text { of the vehicle during } \\
\text { longitudinal and simultaneous } \\
\text { lateral vehicle motion control. } \\
\text { Driver must supervise the } \\
\text { system at all times. }\end{array}$ & SYSTEM & DRIVER & DRIVER & LIMITED \\
\hline \multicolumn{7}{|c|}{ SYSTEM PERFORMS ALL DYNAMIC DRIVING TASKS } \\
\hline 3 & $\begin{array}{l}\text { CONDITIONAL } \\
\text { AUTOMATION }\end{array}$ & $\begin{array}{l}\text { Automated driving with the } \\
\text { expectation that the driver } \\
\text { must react to a request to } \\
\text { intervene. }\end{array}$ & SYSTEM & SYSTEM & $\begin{array}{l}\text { FALL- } \\
\text { BACK-READY } \\
\text { USER }\end{array}$ & LIMITED \\
\hline 4 & $\begin{array}{c}\text { HIGH } \\
\text { AUTOMATION }\end{array}$ & $\begin{array}{l}\text { Automated operation of the } \\
\text { vehicle with the expectation } \\
\text { that the driver will react } \\
\text { to a request to intervene. } \\
\text { Without human reaction, the } \\
\text { vehicle continues to drive } \\
\text { autonomously. The driver } \\
\text { does not have to supervise the } \\
\text { system at all times. }\end{array}$ & SYSTEM & SYSTEM & SYSTEM & LIMITED \\
\hline 5 & $\begin{array}{c}\text { FULL } \\
\text { AUTOMATION }\end{array}$ & $\begin{array}{l}\text { Fully automated driving, with } \\
\text { the dynamic driving task being } \\
\text { performed under all on-road } \\
\text { and surrounding conditions as } \\
\text { if by a human driver. }\end{array}$ & SYSTEM & SYSTEM & SYSTEM & UNLIMITED \\
\hline
\end{tabular}


Figure 4.1.4: Operational design domain

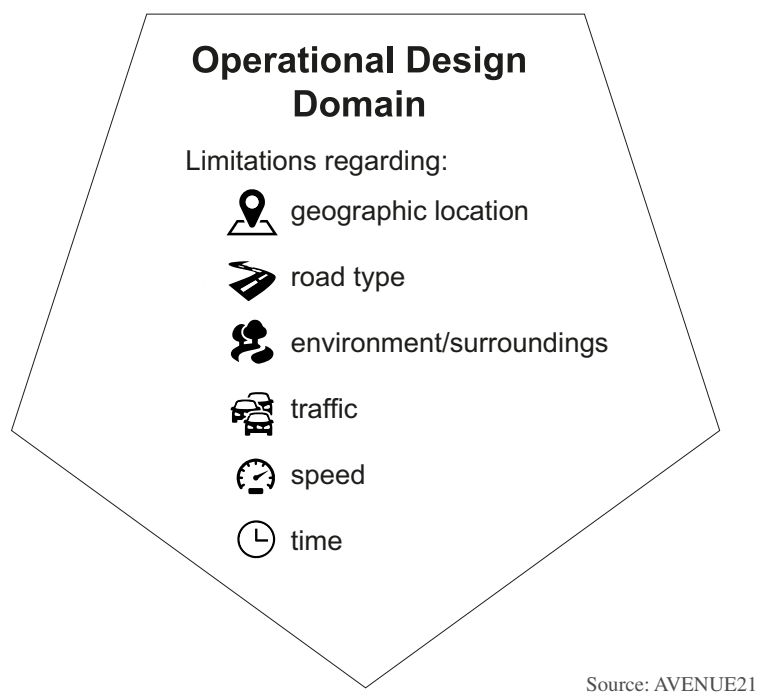

all situations automatically, but whose driverless operation only takes place in areas specifically designed for this purpose (operational design domain-specific); there is no request for driver intervention (Level 4). Finally, vehicles whose systems take over all driving tasks for all road types, speed zones and conditions (regardless of the ODD), and which are therefore operated from the start of the journey to its destination without a driver, are referred to as fully automated vehicles (Level 5; SAE International 2018: 19).

The operational design domain (ODD) describes the conditions under which an automated driving system functions. The parameters of these conditions may include geographic location, road type, surroundings, traffic, speed, time (see Fig. 4.1.4; SAE International 2018: 12).

\section{LEVEL 4: AUTOMATED DRIVING SYSTEMS FOR SPECIFIC CONDITIONS (OPERATIONAL DESIGN DOMAINS)}

The difference between automated driving systems (ADSs; SAE International 2018) that function under limited conditions (ODD-specific; Level 4) and those that function without limitations (ODD-unspecific; Level 5) truly is vast.

However, outside of these specific conditions or ODDs or when these conditions/ODDs change too dramatically, Level 4 automated driving systems are no longer functional (NHTSA 2017: 6). Should a transition to manual driving be necessary, then the driver is requested to take over the driving tasks. If they are not capable of doing so, the vehicle is returned to a risk-minimized system state (VDA 2015: 15; Wagner/Kabel 2018: 317).
Level 4 automated driving systems or applications have been in use since the 1990s. One well-known example in Europe is the park shuttle that connects the Rivium Business Park with the Rotterdam metro as a last-mile feeder line. The second generation of the park shuttle has been operating since 2006 over a distance of roughly 5 kilometres with the same number of stops. The limitations of the ODD were solved infrastructurally: the park shuttle drives on an asphalted route, which is separated from its surroundings on both sides by a one-metre-high fence and a hedge.

Yet in future, technological progress could see the operation of Level 4 automated driving systems without such major infrastructure measures as a structural divider or separate lanes (Hollestelle 2018: 24). Ultimately, such measures always serve to reduce the complexity of the automated driving system's ODD (e.g. avoiding interaction with cyclists) and hence the demands on the automated driving system.

\section{SELECT LEVEL 4 AUTOMATED DRIVING SYSTEMS, THEIR OPERATIONAL DESIGN DOMAIN AND APPLICATIONS}

Level 4 automated driving systems can have different use cases (Wachenfeld et al. 2015: 12), which are defined by the features of their respective ODD and other attributes, such as the possible application or use concept. Various Level 4 automated driving systems that are currently being discussed are designed for very different ODD and for different possible applications (Shladover 2018: 194). The result is numerous possible use cases for such automated driving systems (Fig. 4.1.5).

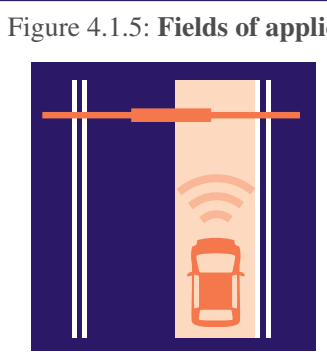

MOTORWAY ASSISTANT
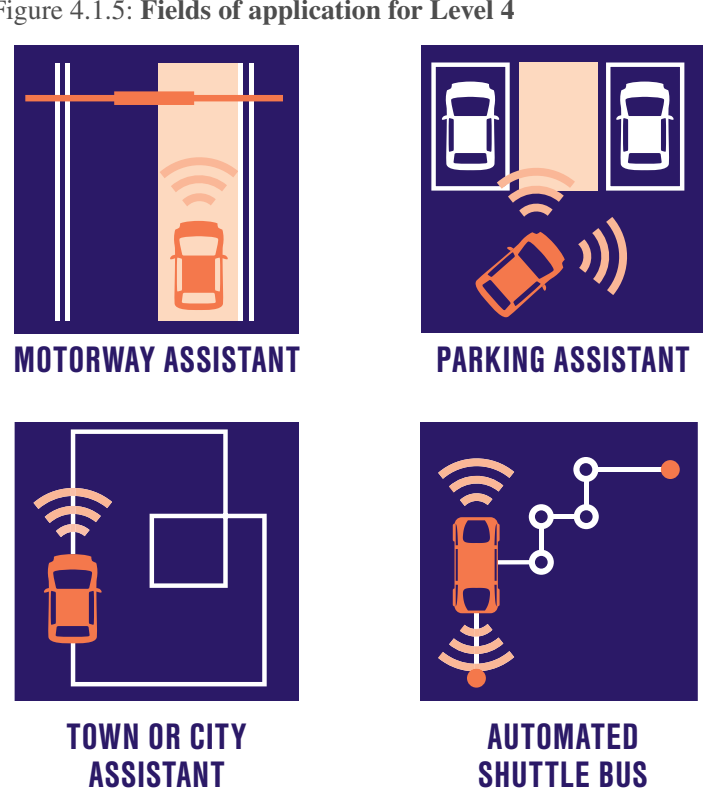

Source: AVENUE21 
A selection of current possibilities for Level 4 automated driving systems as well as their ODDs and applications are discussed below. The overview is limited to four applications.

\section{MOTORWAY ASSISTANT}

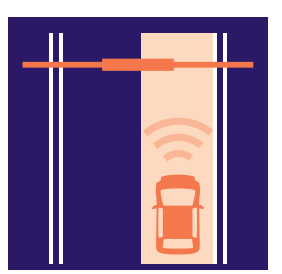

With the motorway assistant, the system exclusively takes over dynamic driving tasks on motorways or other trunk roads. During the journey on the motorway, no awareness of their surroundings is required of the passengers, who can instead occupy themselves with other activities (Wachenfeld et al. 2015: 12). The development of motorway assistants is primarily being encouraged by vehicle manufacturers, but is currently still in the development stage: for example, with the new A8, Audi is planning to market the first production vehicle with a motorway chauffeur (Level 3 ), which can only complete simple driving tasks in good weather conditions.

As initially described, the driver must therefore be capable of potentially taking over if the system requests them to intervene (Schrepfer et al. 2018: 32; Ritz 2018: 30). However, the further development of this system by vehicle manufacturers will lead to a constant increase in the possible dynamic driving tasks on motorways that the system can carry out to the point that a Level 4 motorway assistant is reached, which would allow the driver to read a book or sleep while the motorway assistant is driving on the motorway (Ritz 2018: 31). This would take the pressure off not only car drivers but also drivers of utility vehicles or lorries (Eckstein et al. 2018: 9) and be used for coaches travelling long distances.

Particularly with regard to lorries, motorway assistants are frequently discussed for lanes that are reserved for the exclusive use of lorries in order to reduce the demands on the driving system. These adaptations of the ODD take place with the aim of expediting the roadworthiness of such a Level 4 driving system (Shladover 2018: 194)

\section{PARKING ASSISTANT (AUTOMATED VALET PARKING)}

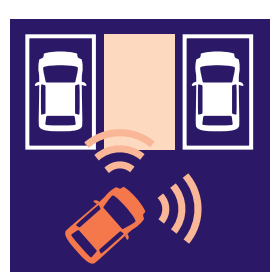

Evidently, vehicle manufacturers' focus in terms of automating passenger cars appears to be mainly targeted at motorways or motorway-like roads (Schrepfer et al. 2018: 34). However, manufacturers like Audi or Daimler are also woring to develop parking assistants/automated driving systems that enable automated valet parking (Ritz 2018: 30).
With automated valet parking, the automated driving system drives to a nearby or far-away parking space once the passengers have left the vehicle. The driver therefore saves time that would otherwise be spent searching for a parking space or actually parking the vehicle (Wachenfeld et al. 2015: 15; Shladover 2018: 194). At present, such automated valet parking is mostly being tested in large car parks, i.e. not in the road network but in places that can be described as distinct settings: Daimler and Bosch, for example, are testing such a system in an indoor car park in Stuttgart, where the vehicle is simply left in a drop-off area and then parks automatically after a command has been activated on the driver's smartphone and automatically drives to a pick-up area after another smartphone command has been selected (Daimler 2018).

In future, such automated driving systems might operate not only in distinct settings, but also in defined and approved areas of the low-capacity road network (e.g. inner-city areas). That would allow the driver to stop right outside a restaurant, for example, and then task the vehicle with automatically finding, driving to and parking in a free parking space once they have got out of the vehicle (Eckstein et al. 2018: 9). However, this would mean that the parking assistant would closely resemble a city assistant (see next paragraph). Due to the advantages associated with this automated driving system (the vehicle picks up its passengers nearby), the development of the parking assistant is being considered not only for private cars, but also - on the part of the manufacturers (e.g. BMW and Daimler) - increasingly in connection with considerations of their own car-sharing services (Drive-Now and Car2go; Ritz 2018: 114; Lenz/Fraedrich 2015: 185).

\section{TOWN OR CITY ASSISTANT}

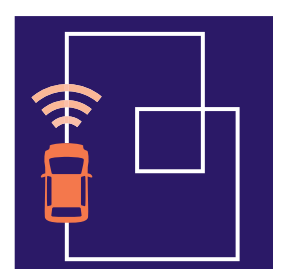

Vehicle manufacturers, which are increasingly presenting themselves as mobility providers, are also working - partly together with new players on the mobility market like Uber or Waymo - on automated driving systems for quite "urban" conditions or defined parts of the lower-capacity road network (Ritz 2018: 135). Current examples include the development of a city assistant by Audi, the tests by Waymo in a designated 100 squaremile area in Chandler, a (suburban) outlying district of Phoenix in Arizona, and the announcement by Daimler and Bosch that they will jointly release Level 4 vehicles in an urban setting over the coming decade (Hawkins 2017; Ritz 2018: 30; Daimler 2018).

In this case, the automated driving system - often referred to as a town or city assistant - takes over the driving tasks in a defined and approved part of the lower-capacity road network. The driver thus becomes a 
passenger in this setting (Wachenfeld et al. 2015: 17; Altenburg et al. 2018: 4).

As a result of the advantages of automated driving systems in this context (e.g. the possibility for a door-to-door service; Lenz/Fraedrich 2015: 185), such systems are increasingly related to concepts like car sharing and ride sharing and then frequently called automated private or shared taxis. The boundaries between MPT and PT are more and more fluid, because in such use cases both vehicle manufacturers and new players on the mobility market see the opportunity for new business models, while public transport companies could expand their service provision by offering such flexible automated driving systems, especially in the suburbs. In principle, the aim with such automated driving systems is that the passenger can contact the control centre in an emergency and pay for the journey via smartphone (Eckstein et al. 2018: 9).

Such automated driving systems are not only being discussed for passenger but also for goods transport, especially as a solution for the last mile. They are intended to take over the last mile from an inner-city warehouse or offline shop to a customer in a defined and approved part of the lower-capacity road network. One example are the vehicles frequently referred to as delivery robots by the manufacturer Starship Technologies, which have a container in which a parcel can be placed (Vogler et al. 2018: 152). Currently, the majority of such automated driving systems are still in operation in business parks (e.g. in Mountain View, USA) or other special zones (where there may have been such automated driving systems, such as for in-house transport, for a long time; Flämig 2015: 378; Hern 2018). Here, too, it is a matter of reducing the demands made of the automated driv- ing system. Generally, however, such driving systems are intended to operate at a speed of max. $6 \mathrm{~km} / \mathrm{h}$ on footpaths in defined, approved areas. They have already been tested in this form in Hamburg (together with Hermes) and Düsseldorf, among other places.

\section{AUTOMATED SHUTTLE BUS}

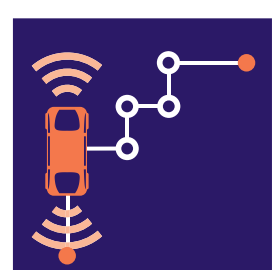

At present, automated shuttle buses are primarily being tested by public transport companies. Examples include the shuttle bus tests by the Deutsche Bahn (DB) in Bad Birnbach, by the Wiener Linien in Vienna and by the PostAuto Schweiz AG in Sitten in Switzerland. The best-known manufacturers of these automated shuttle buses are the companies Navya and EasyMile. The shuttle buses are mostly designed for a capacity of 8 to 12 passengers and according to their manufacturers can reach a maximum speed of $45 \mathrm{~km} / \mathrm{h}$ (Navya 2017: 13); nevertheless, most of them are operating at speeds of just 15 to $20 \mathrm{~km} / \mathrm{h}$ (Zankl/Rehrl 2017: 38; Postauto Schweiz AG 2016).

The automated shuttles are predominantly being tested by the public transport companies as possible feeders for the main underground and suburban railway lines and hence as an expansion of the PT network, for example in the suburbs (Michelmann et al. 2017: 2). The potential personnel-related cost savings as well as the more flexible deployment of such vehicles due to their smaller sizes are viewed as financial relief for the operation of PT in such areas (Lenz/Fraedrich 2015: 191;

Figure 4.1.6: Select automated driving systems and their operational design domain

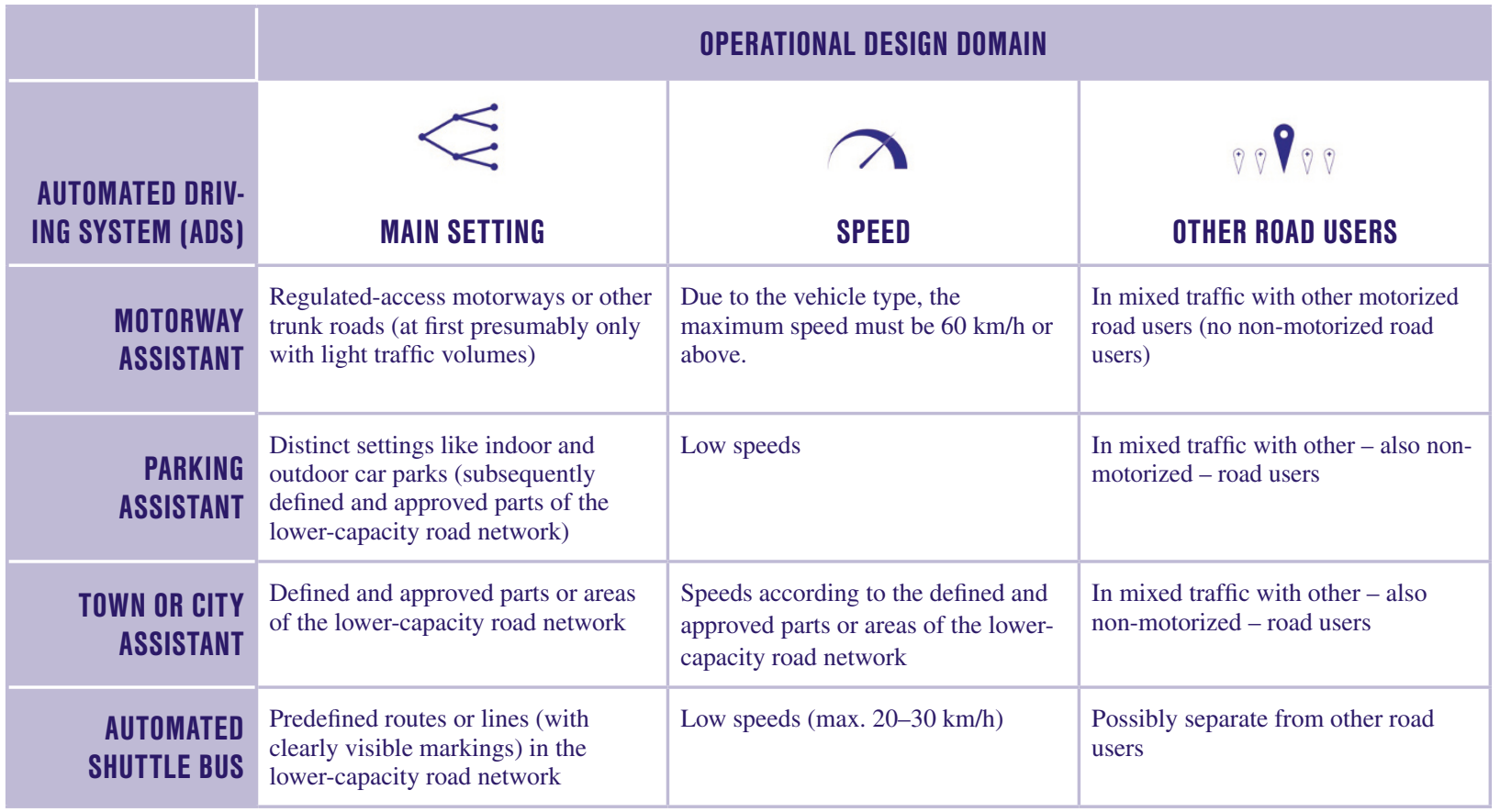


Haider/Klementschitz 2017: 7; Eckstein et al. 2018: 9). It can be assumed that automated shuttles will only run on select, defined, approved and clearly marked routes (and lanes) at first and stop at predefined stations. In these areas, they can operate without drivers, but will be supervised and where necessary manoeuvred by traffic controllers in a control room, similar to the established procedure in aviation (Eckstein et al. 2018: $8)$. In the course of continuous technical development, the area of operation for such automated driving systems might ultimately extend to defined and approved parts of the lower-capacity road network. The automated driving system of automated shuttle buses would thereby approximate a city assistant - combined with the concept of ride sharing.

\section{SUMMARY}

In summary, the range of automated driving systems described above can be categorized on the basis of the geography or setting in which they can operate, which comprises several parameters of the ODD. In simple terms, these categories are: (1) motorways and other trunk roads, (2) parts of the lower-capaci- ty road network, (3) routes in the lower-capacity road network and (4) distinct settings (Fig. 4.1.6). Whereas the motorway assistant focuses exclusively on motorways and other trunk roads, the parking assistant (valet parking) functions in the first instance only in distinct areas like car parks. In contrast, the so-called city assistant concentrates on defined and approved parts of the lower-capacity road network, while the automated shuttle bus runs primarily on defined routes in the lower-capacity road network. In future, Level 4 automated driving systems might also cover combinations of these scenarios. Technical developments will ultimately culminate in a Level 5 automated driving system, which will function in all contexts or settings (ODD-unspecific), and (to the greatest possible extent) without limitations (Shladover 2018: 195).

The Level 4 automated driving systems described here are relevant for both passenger and freight transport, but only in distinct sections of the road network (Fig. 4.1.7).

The motorway assistant can be used for both private cars and logistics vehicles like lorries and vans, and even coaches. The parking assistant is primarily being discussed in the context of private cars or A-segment

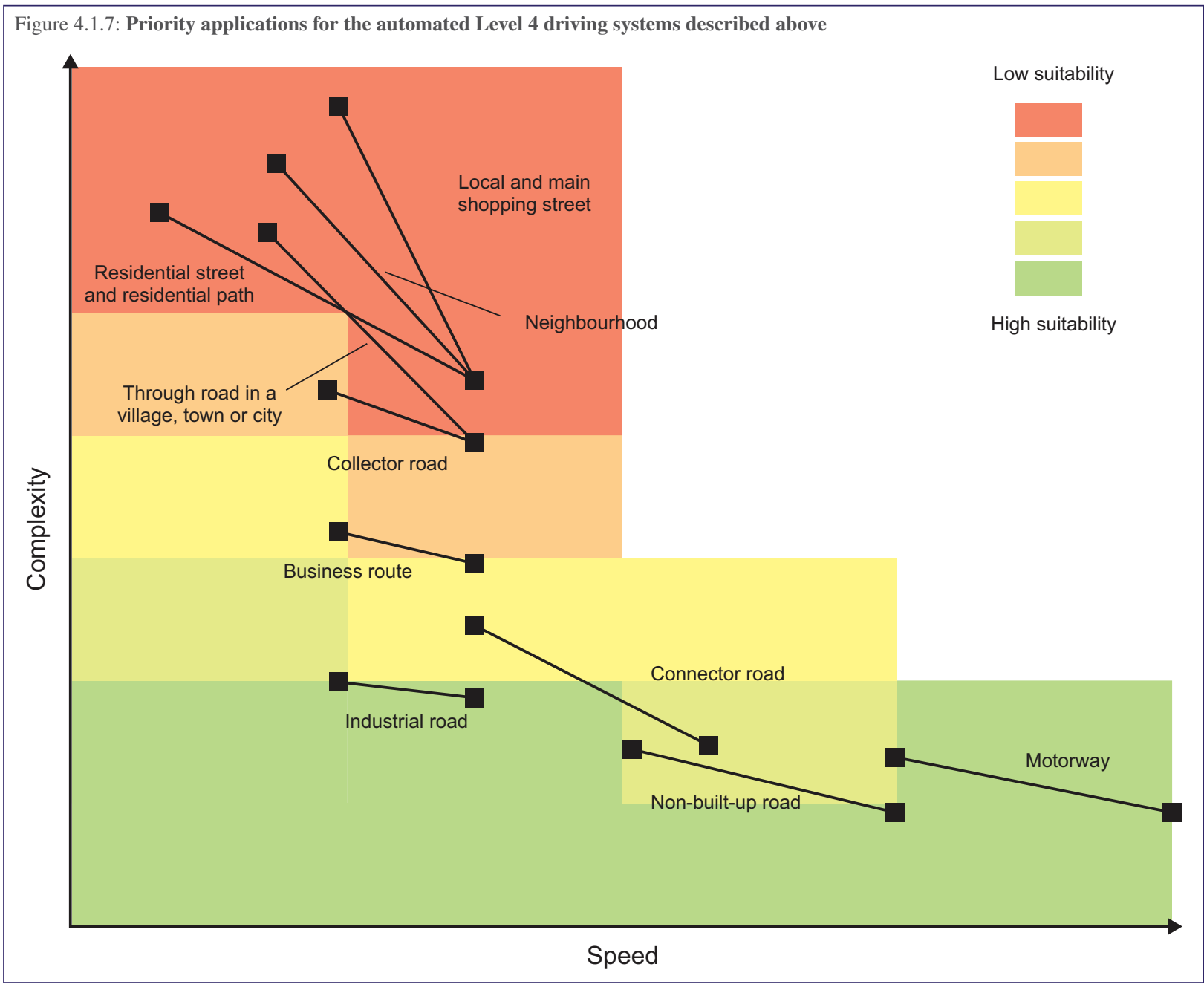


vehicles like pods or LSEV (low-speed electric vehicles), as well as in connection with car sharing (private taxis). The so-called city assistant can be used both for private cars and A-segment vehicles, but also for car sharing (private taxis) and ride sharing (shared taxis) the boundaries are blurred here between individual and collective passenger transport - as well as for (lastmile) logistics vehicles. The automated shuttle bus is being considered in public transport, where it would have pre-established or flexible stops and operate as a free-floating or route-based system.

\section{THE IMPORTANCE OF LONG LEVEL 4 FOR URBAN AND MOBILITY PLANNING}

The term ODD was only adopted by SAE in 2016 and has since been growing in significance: both in the development of the technology and in urban and mobility planning. A prolonged transition period in which automated vehicles are possible and in use, though only in specific environmental conditions, results in a staggered time frame. This staggering is a consequence of the complexity that characterizes urban streetscapes in particular. The opinion that CAVs will be implemented homogeneously in cities is hence outdated. Rather, various applications will be implemented in selective spaces in European cities and will hence only be available to certain sections of the population. Furthermore, this will result in a possible shift in location quality, with some locations being connected to a supra-regional transport network and others not. Consequently, the possible changes to the city as a result of automated vehicles will only take place in individual areas at first (Ritz 2018: 74). Chapter 4.4 takes a close look at this issue. As shown in the scenarios in Chapter 5, this limitation raises both the need and scope for action by urban and mobility planners.

\section{CONNECTING VEHICLES}

In the context of vehicles' automation, their connection with one another or with their surroundings is increasingly playing a major part (Rammler 2016: 14; Bönninger et al. 2018: 97). In the majority of the applications described above, especially car and ride sharing, connection is essentially the prerequisite for users being able to access the automated vehicle via app or web portal (Johannig/ Mildner 2015: 4).

Vehicles' capacity to connect with one another is categorized according to the thing or person with which/whom the connection is established. "Vehicle to everything" or V2X (the sum of all functions in Fig. 4.1.8) describes vehicles' complete communication ability: whether with one another (V2V), with infrastructure (V2I) or with pedestrians' mobile devices (V2P; Shladover 2018: 191).
The possible applications range from dynamic and highly concentrated (goods) platoons as well as connected collision warnings and danger alarms $(\mathrm{V} 2 \mathrm{~V})$ to real-time information about weather and road conditions (V2I) to shuttles that communicate their status directly with pedestrians or predictively with pedestrians' mobile devices (V2P; Owens et. al 2018: 71; Shladover 2018: 191). Moreover, users should have the option to be seamlessly mobile from departure to arrival depending on their situation (Boban et. al 2017: 2). Figure 4.1.8 provides an overview of the different connection types and their possible applications.

The prerequisite for this is the reliable and stable, and most importantly highly efficient and quick, sharing of information or data on the basis of communication technologies, sensors and network connections (Maracke 2017: 64). The industry differentiates here between long and short latency times. While the latter primarily concern collision warnings, speed limits or electronic payments for parking and tolls, the former are mainly related to infotainment and traffic information services on long journeys.

Various wireless communication technologies can be used to share this data (Shladover 2018: 192). The most applicable technologies are ITS-G5 (WLAN IEEE 802.11p), cellular networks (LTE-Vehicular/LTE Advanced or in future $5 \mathrm{G}$ ) and digital broadcasting such as DAB (Digital Audio Broadcasting), DAB+, DMB (Digital Multimedia Broadcasting) or DAB-IP. At present, it is still entirely uncertain which communication technology will prevail in the context of automated driving systems: while the European Commission is pursuing the idea of a complementary communication mix with the application of hybrid communication technologies, in the USA a single (short-range) communication technology is preferred by the National Highway Traffic Safety Administration in draft legislation on the ITS-G5 standard (Sänn et al. 2017: 62).

As a result of the growing importance of vehicles' connection, the requirements for security and data protection are being raised (Lemmer 2015: 61). Every connected vehicle collects considerable amounts of at times sensitive data and information on movement patterns, personal travel habits or financial matters, which must be not only saved but also analysed and secured. Without security standards, the more automated and connected vehicle systems become, the more vulnerable they will be to outside attacks and to malfunctions (Seider/Schmitz 2017).

Regarding communication from vehicle to vehicle or between the vehicle and its manufacturer's servers, it must therefore be ensured that there is adequate protection from attacks by hackers, that data integrity is guaranteed and that communication is robust. In addition, it is imperative that the systems cannot simply be stopped 
by denial-of-service attacks (e.g. a distributed denial of service or DDoS; Ritz 2018: 205). Ultimately, the topic of connection - especially in light of user acceptance - is closely related to guaranteeing data privacy and protection from cyberattacks (Seider/Schmitz 2017 and Chap. 3.4).

\section{THE IMPORTANCE OF CONNECTION FOR URBAN AND MOBILITY PLANNING}

The issue of connection is significant for cities. Connection with infrastructure (traffic lights, traffic information or control systems) means a considerable financial outlay (Mitteregger et al. 2019). To organize and access multimodal mobility services, the connection of vehicles as well as different operators' fleets is crucial. If cities want to play a part in organizing sharing services, then access to data is fundamental. Data will also be of growing importance in future for traffic information systems and to steer flowing traffic by means of toll systems. These data can in turn be generated by municipal investments in digital infrastructure or by requiring the operators of sharing fleets to communicate this information with the city (Chap. 3.3).

Figure 4.1.8: Overview of connection types and their possible applications

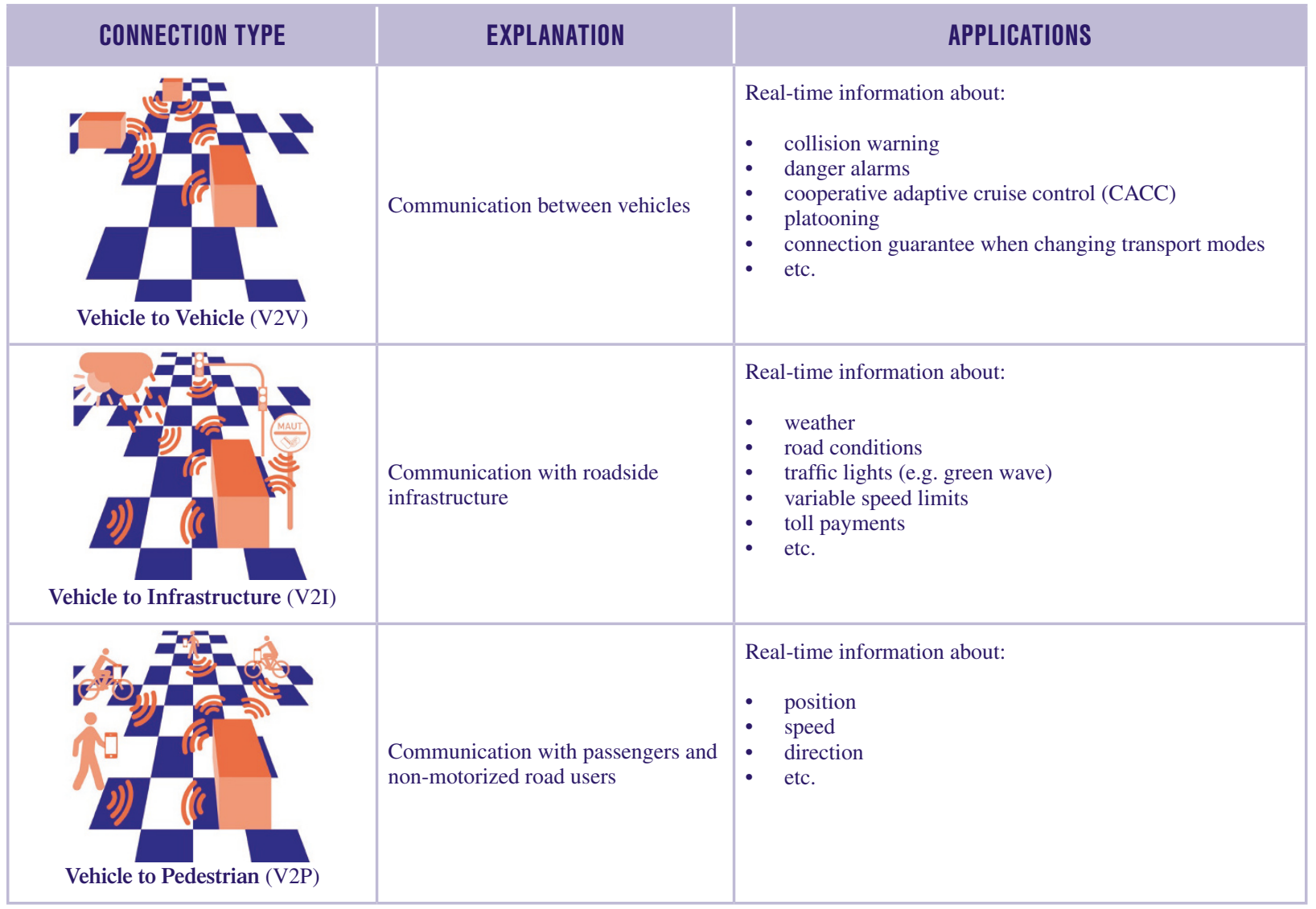


4.2

\section{SETTLEMENT AND INFRASTRUCTURE ASPECTS OF SPATIALLY SELECTIVE IMPLEMENTATION}

The development of settlements and cities is closely connected to transport or rather to technological innovations in mobility. While journeys were almost exclusively undertaken on foot until the mid-19th century, only a short time later horse-drawn carriages and buses, trains, trams, undergrounds and then cars became the main modes of transport and accordingly left their mark on settlement development (Fig. 4.2.1; Safdie/Kohn 1998: xii). Today, it is easy to draw a connection between mobility technologies and the development of European cities, their variety of historic, medieval districts and more recent neighbourhoods. Consequently, the evolution of settlement structures - meaning settlements' expansion, inner structure and spatial distribution - reflects the historical development of transport systems: the means of transport available, the popular transport routes and above all the speeds of transport modes (Schmitz 2001: 27).

Both the vehicles themselves and the transport infrastructure (rail and road networks, harbours and airports) were the decisive factors regarding which mobility innovations would have an influence on life in and the structure of settlements. The history of infrastructure is also one of innovations, which frequently go unmentioned (McShane 1994). Infrastructure is the immobile component that is essential if new modes of transport are to have a spatial impact (changes to accessibility and land use as well as associated economic and social effects). (In Europe) it is often the public sector that makes funding available for the construction and maintenance of transport infrastructure. The economic sense of investments in transport infrastructure is therefore a much-discussed transport policy issue (Aschauer 1989, Deng 2013). This aspect will be the focus of our study of CAT in SAE Level 4 in this section. As Level 4 driving systems can only be implemented in parts of the road network, they may require investments in or expansion of infrastructure.

\subsubsection{SETTLEMENT DEVELOPMENT AND MOBILI- TY INNOVATIONS: LOOKING BACK}

In the Middle Ages, European cities were mostly characterized by high density, narrow streets and crowdedness. This resulted from the necessity for fortifications around the city, which in turn were needed because of the relative spatial proximity of cities to one another, and from the fact that most journeys had to be undertaken on foot (Mumford 1984; Wegener/Fürst 1999: 4). The pedestrian network remained the transport system that defined urban development until well into the 19th century. These cities' structure accordingly revolved around walking distances: cities were small and cohesive urban units and the diameter of the urban area

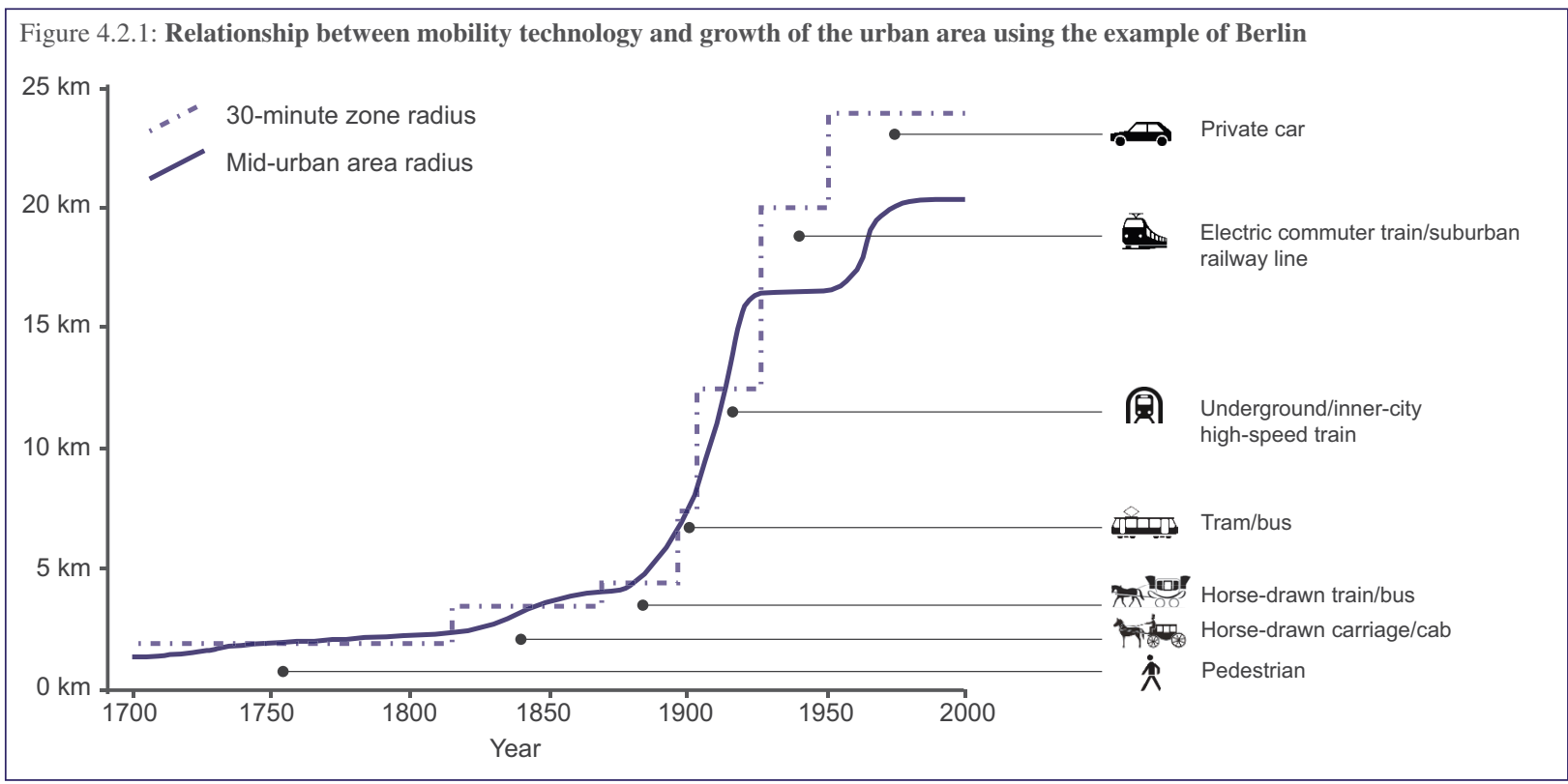

Source: AVENUE21 after Kagermeier (1997: 25) and Lehner (1964: 22-23) 


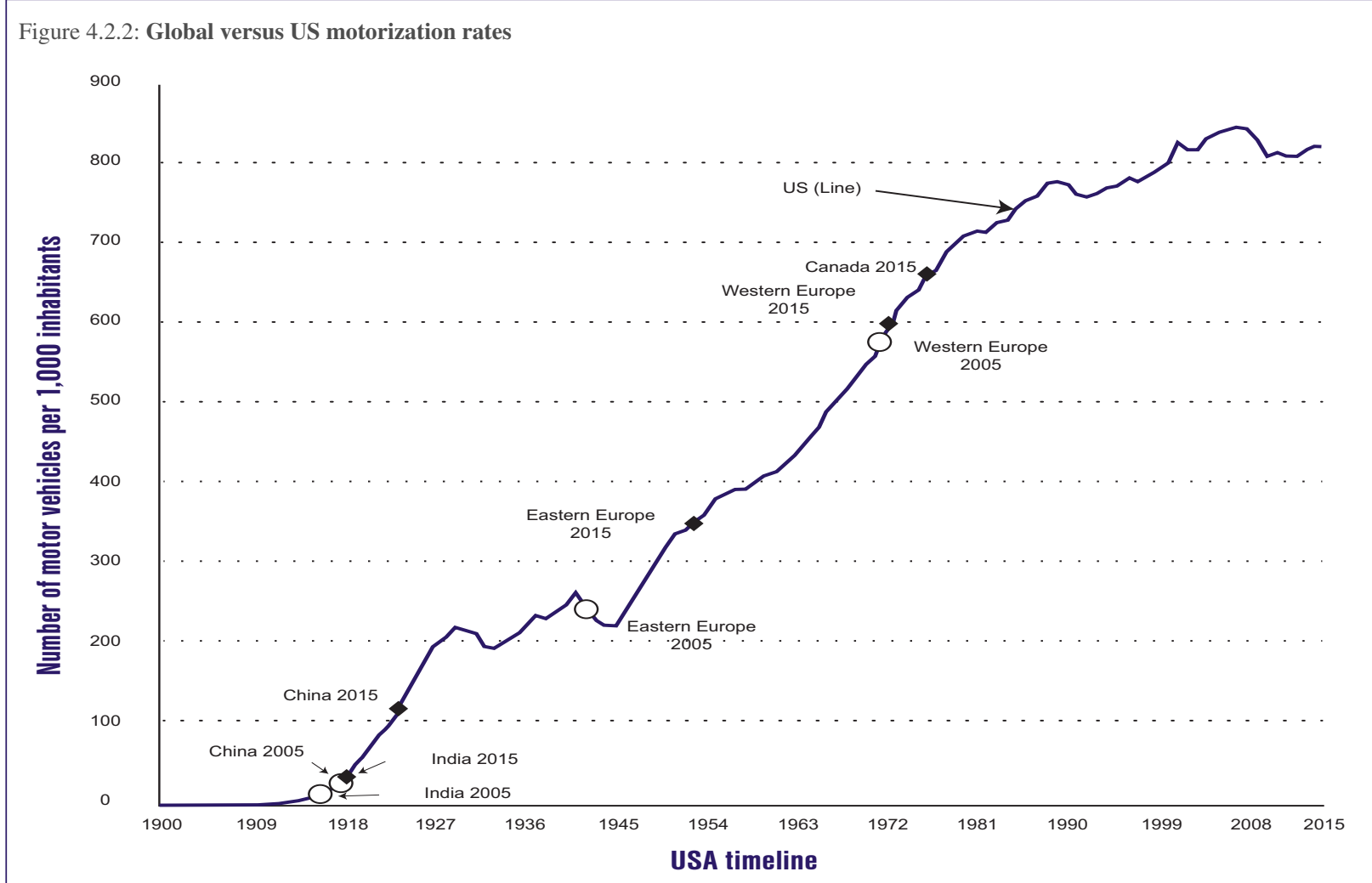

Source: Davis et al. (2015: 3-8)

rarely exceeded five kilometres (Kainrath 1997: 16). Such structures can still be found today in the medieval centres of numerous European cities (Newman/Kenworthy 1999: 28). With the advent of horse-drawn buses, trams, supra-regional trains, wooden and iron rails and new road surfaces (stone, brick and wooden paving, tarmac and finally asphalt) in the 18th century, accessibility and subsequently settlement structure changed (Kainrath 1997: 16). A fundamental shift in the social significance of mobility and the streetscape took place (McShane 1979: 57-80).

The last far-reaching change in mobility was brought about by the growing popularity of the private motor car over the course of the 20th century. Beginning in the USA (where asphalt road surfaces also spread more rapidly), it spread to Europe after World War II. The extensive accessibility afforded by cars now made it possible to use areas between railway lines for city expansion (Wegener/Fürst 1999: 5). In addition, the general increase in prosperity associated with the postwar economic growth in Europe led to widespread individual motorization. The prevalence of private cars simultaneously enabled and encouraged the spatial separation of functions like living and working (Kagermeier 1997: 24). The result was less organized and more dispersed urban growth accompanied by high levels of urban sprawl on the outskirts (Wegener/Fürst 1999: 5). The urban fringe is still dominated by car travel today as there are considerable gaps in public transport provision (Kainrath 1997: 16).

\subsubsection{RATE OF CHANGE: THE DIFFUSION OF TRANSPORT TECHNOLOGIES}

Before transport technologies can have a spatial impact, they must first be accepted by a growing number of people and be used in everyday life. These are long-term processes - a fact that is often overlooked (King/Baatartogtokh 2015) by the theory of disruptive technologies (Christensen 2003). The diffusion of innovations (Rogers 2003) is a communicative process during which individuals or social groups choose to adapt and hence to accept the effort that goes along with such change. The diffusion starts slowly, gathers pace and then loses speed as soon as saturation effects emerge. This has proven to be a valid finding (Kucharavy/De Guio 2011, Grubler et al. 2016).

The duration of technological diffusion processes depends on a range of factors. They include the complexity of the technology, the length of the "formative phase" (Bento/ Wilson 2016), the effort needed to change existing habits, the amount of investment required for its introduction, the expected advantages for various groups and whether legal amendments or new regulations are necessary.

Figure 4.2.3 summarizes the characteristics of long diffusion processes as described by Grubler et al. (2016) and applies them to CAT. The high global prevalence of road traffic and the large number of individuals who will be affected by changes to transportation and the streetscape are principal factors affecting the duration 
of the diffusion process for CAT. In addition, there is considerable need for coordination between various political levels and stakeholders (see Chap. 4.6), e.g. in order to certify diverse automated driving functions and vehicle types (Walker 2016). Moreover, standards for the physical and digital infrastructure and to ensure certain ODDs must be coordinated and implemented (European Commission 2017, 2019). Furthermore, major investments are expected to be necessary at various levels of the road network, which will present a not insignificant challenge to states and municipalities (POLIS 2018, Mitteregger et al. 2019). In terms of the technological development, the amalgamation of different sensor data to produce a coherent picture is a key challenge, which has not been required to this extent for any other use case (see Chap. 4.4).

\section{ISSUES OF AUTOMATIC DRIVING SYSTEMS' ACCEPTANCE}

The response to the question of CAVs' acceptance is determined by the duration of the diffusion process. This affects not only the travellers (passengers), but also all other road users. It should not be underestimated that with Level 4 "driving robots", the first time people have to interact with automated mobile machines in public space is in critical (and potentially lethal) situations. To date, this experience is still limited to those working in sectors like logistics (e.g. in ports or logistics centres), agriculture, mining or the military (drones). Figure 4.2.4 summarizes the principal areas of acceptance currently being discussed in the specialist literature.
CAV passengers must learn to accept that they are being driven by a software-controlled machine that steers and supervises all activities during the journey, and that can potentially be affected or directed by external entities (police, mobility service provider, infrastructure operators, but also hackers). Interacting with the vehicle as a passenger will be a major hurdle for certain social groups (trust, familiarity with technology, the digital divide). Yet also for other road users who will have to adjust their behaviour in public space to that of the automated driving system, there is a pressing need to establish trust (which is being addressed in current test situations by means of signals on the vehicles). In the case of CA ride sharing, the relatively small space inside the vehicle is shared with strangers for the duration of the journey without the presence of a driver, a factor that - in light of increasing social differentiation - will lead to acceptance being low and potentially sinking in sparsely populated areas and in off-peak periods at first (Merat et al. 2017). This applies particularly to groups with limited mobility who are supposed to benefit the most from these shuttle services.

A low acceptance of automated vehicles might lead to behaviour in the public space of the street once again changing fundamentally (as was the case with the advent of cars, see Chap. 3.2). During operation, automated driving systems will gather comprehensive data in public space - including on people's behaviour in the streetscape - and utilize them in the context of data-based business models or traffic management. Comprehensive surveillance is rarely accepted in European (in contrast

Figure 4.2.3: Comparison of the characteristics of long technology diffusions and connected and automated driving systems

\begin{tabular}{|c|c|}
\hline LONG TECH. DIFFUSIONS & CONNECTED AND AUTOMATED DRIVING SYSTEMS \\
\hline $\begin{array}{l}\text { Adaptations in organizational and } \\
\text { institutional settings, of several } \\
\text { technologies and of infrastructure } \\
\text { become necessary. }\end{array}$ & $\begin{array}{l}\text { Institutions and organizations first have to create the legislative framework for CAVs and develop } \\
\text { criteria for their authorization or certification (Schoitsch et al. 2016). As a result of transnational } \\
\text { transport networks and the standardized production of vehicles, there is a fundamental need for } \\
\text { coordination at every political level. } \\
\text { - Connected and automated vehicles replace non- or minimally automated vehicles in pre-existing } \\
\text { infrastructure. Even if part of the existing infrastructure can be used, it nevertheless requires major } \\
\text { adaptations. }\end{array}$ \\
\hline $\begin{array}{l}\text { New technological and social } \\
\text { concepts have to be developed or } \\
\text { learned. }\end{array}$ & $\begin{array}{l}\text { - The main technical challenge of CAT is amalgamating different sensor data to produce a coherent } \\
\text { picture. This picture has to be interpreted by machines (via artificial intelligence) and serves as the } \\
\text { basis for traffic control and driving decisions (see Chap. 4.6). } \\
\text { - The interaction of non-human actors with other road users poses new socio-psychological challenges, } \\
\text { which must be addressed and accepted in the long term (Merat et al. 2017, Rogers 2003). }\end{array}$ \\
\hline $\begin{array}{l}\text { Significant investments in wide- } \\
\text { spread technologies and infra- } \\
\text { structure become necessary, with } \\
\text { the expense of the adaptation } \\
\text { only paying off at a later stage. }\end{array}$ & $\begin{array}{l}\text { Investments could become necessary at every level of the transport network. Of relevance are the } \\
\text { sizes of the motorway and trunk road networks (1.9\% of the transport network in Austria), dual } \\
\text { carriageways (29.3\%) and municipal roads }(68.73 \% \text {; BMVIT 2018) and those responsible in each } \\
\text { case for their maintenance and repair, as well as different kinds of funding (e.g. via toll or transfer } \\
\text { payments). } \\
\text { In addition, further investments may be necessary in the digital infrastructure, the connection of the } \\
\text { vehicles (DG MOVE 2016: } 41) \text {. The scale of these investments differs greatly from place to place } \\
\text { and is not currently foreseeable. }\end{array}$ \\
\hline
\end{tabular}


to Chinese) cities at present. Closely connected to the introduction of CAVs is the transformation from passive to active security systems, which will fundamentally alter the understanding of public streets in European cities in future (Mitteregger 2019).

\subsubsection{THE IMPORTANCE OF TRANSPORT INFRA- STRUCTURE DURING THE LONG LEVEL 4}

Transport infrastructure, and road infrastructure in particular, is deemed to be vitally important for the economic development of regions (Aschauer 1989). Consequently, the planning and construction of transport infrastructure is considered a key structural policy measure. The European Union has allocated some $€ 600$ billion to "complete and modernise a true trans-European network" by 2020 (European Commission 2005: 3). From a structural policy perspective, the European initiative "Cooperative Intelligent Transport Systems" (C-ITS) is believed to be one of the key measures to get CAM off the ground. It covers a broad spectrum of infrastructure applications (from traffic control and management systems to blanket $5 \mathrm{G}$ coverage). C-ITS are intended to increase road safety, boost efficiency and improve comfort (European Commission 2016: 3). Especially in Europe and regarding CAT, the widespread perception among policymakers and planners that roads lead to wealth (Deng 2014: 687 ) should be viewed in a more nuanced light.

\section{SETTLEMENT DEVELOPMENT THROUGH TRANSPORT INFRASTRUCTURE}

The relationship between the effects of transport infrastructure on land use and settlement structure has been confirmed by recent overview studies focusing on various spatial criteria (Deng 2014, Kasraian et al. 2016). However, this relationship is generally more nuanced than usually assumed (Fig. 4.2.5). There is a demonstrable correlation between the extent of development in the settlement area, its current accessibility and the effectiveness of transport infrastructure investments as a structural policy measure. Saturation effects become clear, which arise in areas that are easily accessible and/ or already have a well-developed settlement structure. Consequently, the strongest impacts are to be expected primarily in areas which are not fully developed and to which access can be improved by the construction of new transport infrastructure.

Another feature of improved accessibility as a result of transport infrastructure measures is that, from an economic perspective, it does not benefit all sectors equally (Deng 2014: 691-692). Transport-heavy sectors like logistics and construction profit much more than e.g. the textile industry (Fernald 1999: 628). Cantos et al. (2005) were also able to demonstrate an unequal distribution of accessibility effects with regard to companies' sales markets. For example, those branches that market their products at national or transnational level (indus-

Figure 4.2.4: Criteria discussed in the literature regarding passengers' and other road users' acceptance of SAE Level 4

\begin{tabular}{|c|c|}
\hline CRITERION & STUDIES \\
\hline \multicolumn{2}{|r|}{ PASSENGER } \\
\hline "Being transported" & Hancock et al. 2011, Malodia/Singla 2016, Schaefer/Straub 2016 \\
\hline Ride sharing & $\begin{array}{l}\text { Ahmadpour et al. 2016, Beirao/Sarsfield-Cabral 2007, Chan/Shaheen 2012, Dueker et al. 1977, } \\
\text { Malodia/Singla 2016, Merat et al. 2017, Thompson et al. 1991, Venkatesh et al. } 2003\end{array}$ \\
\hline Surveillance during the journey & Crittenden 2017, Litman 2017, Schulz/Gilbert 1996 \\
\hline Human-machine interaction & $\begin{array}{l}\text { Grush et al. 2016, Hoff/Bashir 2015, Merat et al. 2017, Schaefer/Straub 2016, Seppelt/Lee 2007, } \\
\text { Venkatesh et al. 2003, Wiseman } 2017\end{array}$ \\
\hline Access to external entities & Anderson et al. 2016, Gontar et al. 2017 \\
\hline \multicolumn{2}{|r|}{ OTHER ROAD USERS } \\
\hline Empty runs & Elliot/Long 2016 \\
\hline Human-machine interaction & $\begin{array}{l}\text { Anderson et al. 2016, Grush et al. 2016, Hoff/Bashir 2015, Merat et al. 2017, Parkin et al. 2016, } \\
\text { Rodriguez et al. 2016, Schaefer/Straub 2016, Seppelt/Lee 2007, Venkatesh et al. } 2003\end{array}$ \\
\hline Surveillance on public streets & Anderson et al. 2016, Cirittenden 2017, Schulz/Gilbert 1996 \\
\hline
\end{tabular}


try, manufacturing trades) benefit, while sectors operating regionally (retail, construction, the service industry, agriculture) tend to face losses in profits as a result of improved accessibility.

\subsubsection{CAT AT THE INTERSECTION OF LAND USE AND TRANSPORT}

There is an interdependency between land use and transport and via the key parameter of accessibility, together they form a complex of interrelated effects (Fig. 4.2.6; Wegener/Fürst 1999: 5-6; Bertolini 2012: 19). The effects within the system happen at different speeds: if there is a change in the transport system, this causes an immediate change in accessibility and simultaneously causes corresponding changes in the perception of distances (Kagermeier 1997: 22). As a result, adjusted mobility charges can give rise to new or different functional relationships between pre-existing locations. Similarly, a change in land use or settlement structure leads to a change in accessibility and to a relatively fast shift in mobility activities (within a matter of years or even days; Bertolini 2012: 2).

However, the respective changes in accessibility only have a medium- to long-term impact (over decades) on settlement structure or transport services (Bertolini 2017: 27). Consequently, the change in effort needed to cover distances only has a medium- to long-term effect on construction investors' location decisions (and on their construction work) and on individuals, households and companies, and hence on settlement structure (Kagermeier 1997: 22).

Figure 4.2.5: Spatial impacts resulting from transport infrastructure networks and land use

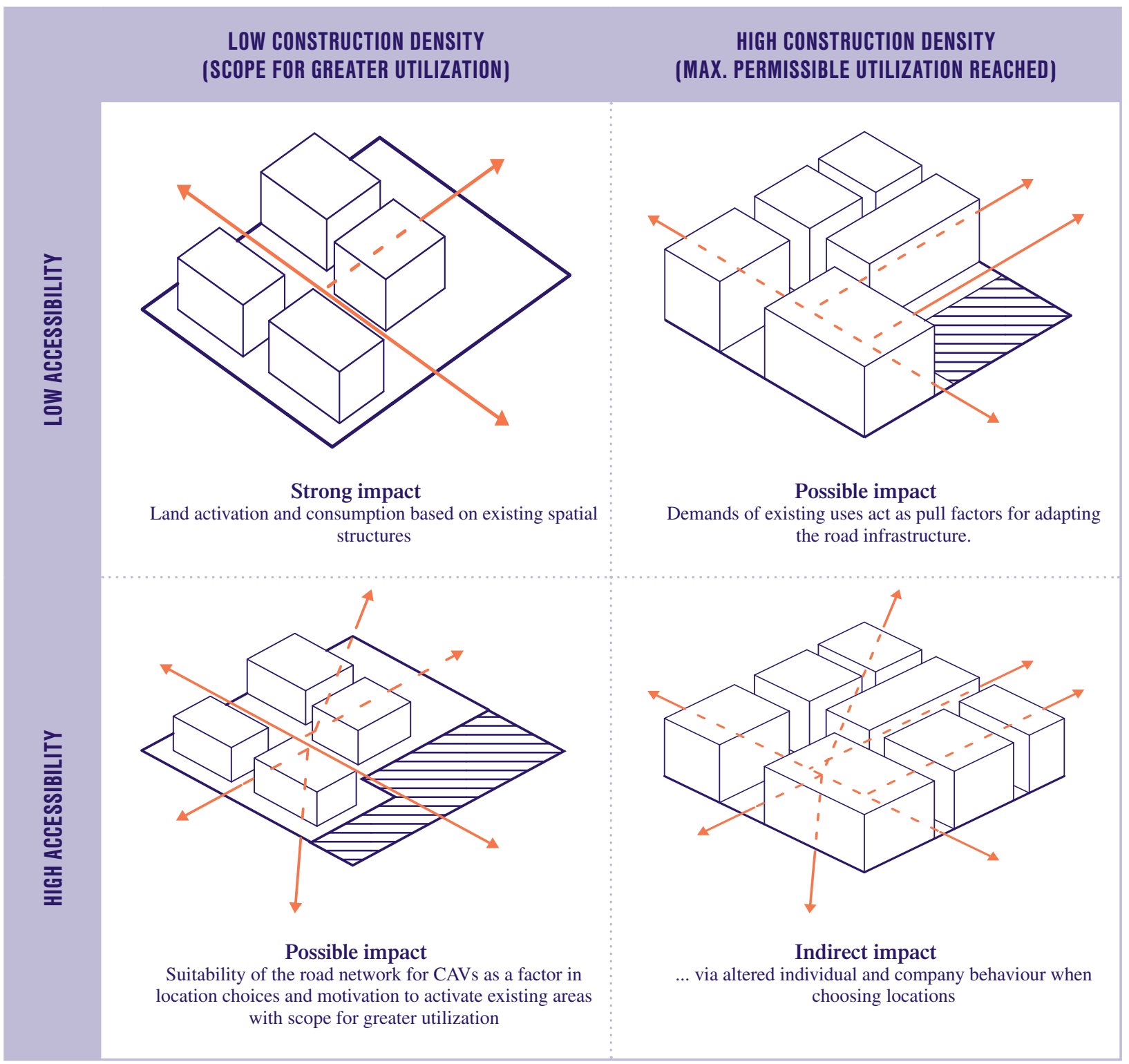

Source: AVENUE21 after Kasraian et al. (2016) 
As a mobility innovation, connected and automated vehicles have enormous potential to transform the transport system. They make different transport services possible, which will lead to changes in the demand for transport (Fig. 4.2.2; Alessandrini et al. 2015: 148; Friedrich/Hartl 2016: 7). In the long term, impacts on urban and settlement development are likely (European Commission 2016: 2). Based on the assumption of a Long Level 4 in which CAVs can only be used in parts of the transport network, a highly dynamic transport and spatial system can be expected. The subsequent consideration of global simulation studies should be read with this in mind.

Figure 4.2.6: Connected and automated transport at the intersection of land use and transport

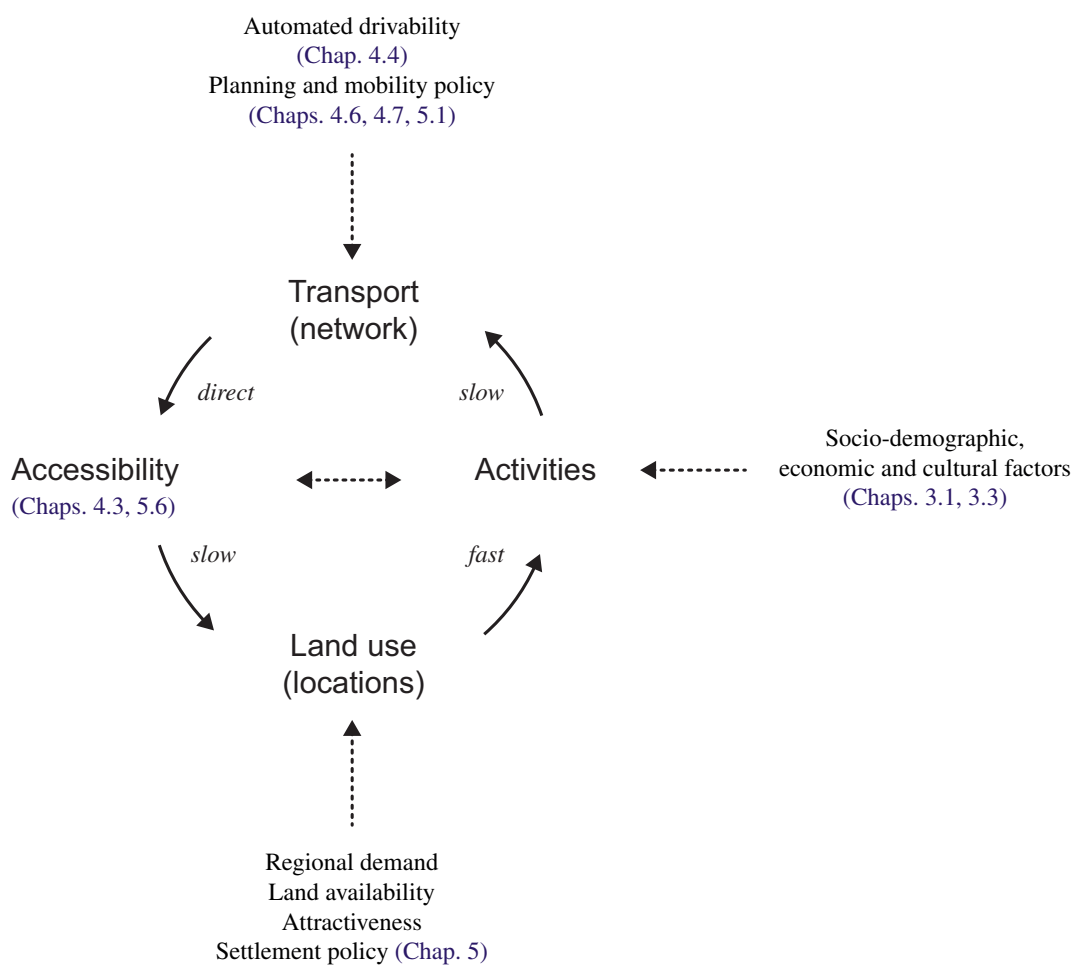

Source: AVENUE21 after Wegener/Fürst (1999) and Bertolini (2012) 
4.3

\section{RESEARCH ON FULLY AUTOMATED VEHICLES' IMPACTS ON THE CITY: STATUS QUO}

Figure 4.3.1: Collated results of the simulations from recent studies

\begin{tabular}{|c|c|c|c|c|c|c|c|c|}
\hline \multirow{6}{*}{ 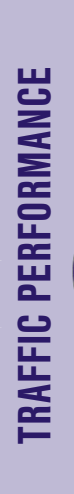 } & \multicolumn{8}{|c|}{ PRIVATE AUTOMATED VEHICLES } \\
\hline & + & (ㄴ) $€ \downarrow$ & 䓃 $\% \uparrow$ & it & + & \multicolumn{3}{|l|}{$\therefore=0 \uparrow$} \\
\hline & $\begin{array}{c}\mathbf{1 5 \%} \% \text { TO } \\
\mathbf{5 9} \%\end{array}$ & $\begin{array}{l}\text { Value of } \\
\text { time }\end{array}$ & $\begin{array}{l}\text { Penetration } \\
\text { rate }\end{array}$ & $\begin{array}{l}\text { Parking } \\
\text { costs }\end{array}$ & $\begin{array}{c}1 \% \text { TO } \\
4 \%\end{array}$ & \multicolumn{3}{|l|}{$\begin{array}{c}\text { Road } \\
\text { capacity }\end{array}$} \\
\hline & \multicolumn{8}{|c|}{ AUTOMATED VEHICLES AND SHARING } \\
\hline & + & (ㄴ) $€ \downarrow$ & لـ & & + & 畐 $\% \uparrow$ & - & Fang $\% \uparrow$ \\
\hline & $\begin{array}{c}\mathbf{3 5} \% \text { TO } \\
\mathbf{6 0} \%\end{array}$ & $\begin{array}{l}\text { Value of } \\
\text { time }\end{array}$ & $\begin{array}{l}\text { Operating } \\
\text { costs }\end{array}$ & & $\begin{array}{c}8 \% \text { T0 } \\
80 \%\end{array}$ & $\begin{array}{l}\text { Penetration } \\
\text { rate }\end{array}$ & $\begin{array}{c}10 \% \text { TO } \\
25 \%\end{array}$ & $\begin{array}{c}\text { Ride } \\
\text { sharing }\end{array}$ \\
\hline
\end{tabular}

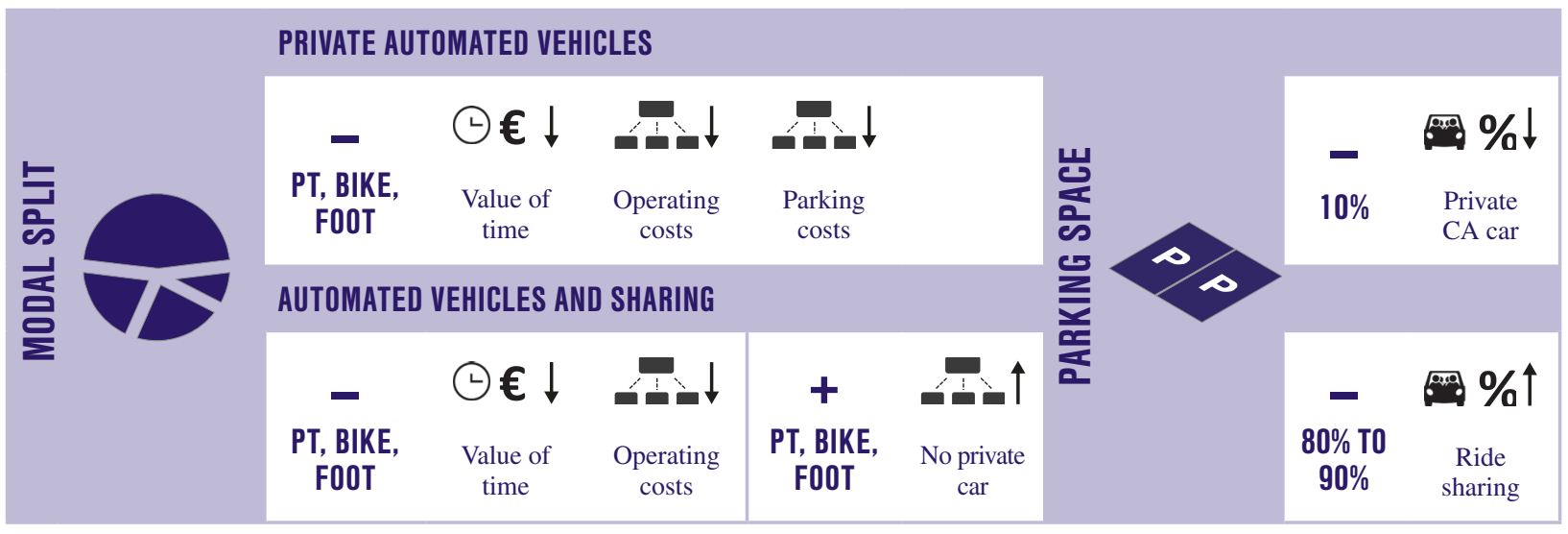

At most, higher-level automated vehicles (simulation studies do not analyse vehicles' connection, which is why this section only discusses automated vehicles) are on the road exclusively in the context of test projects at present. In order to investigate and assess the possible impact of automated vehicles on cities in the future, numerous studies therefore rely on simulations: by using various assumptions and scenarios regarding the forms of transport - including automated vehicles available in future, automated vehicles' possible impact on traffic and urban spaces is simulated with the aid of computers. In addition, there are studies that attempt to assess the effect of automated vehicles on issues such as social justice/inclusion or municipal budgets.

Figures 4.3.1 and 4.3.6 provide an overview of the results of recent studies on the aforementioned issues and a short explanation of the accompanying effects.
Among other things, they comprise road capacity/traffic jams, road safety, transport infrastructure, vehicle ownership, transport demand, parking spaces, settlement structure, social justice, health, the environment, cyber security, the economy and governance (Milakis et al. 2017: 6).

For the purposes of this project, an analysis was conducted of the effects of automated vehicles on transport demand and settlement structure or land use. In total, 37 modelling studies were analysed from various countries around the world, though primarily the USA and Europe (Soteropoulos et al. 2018a). The results show that the way automated vehicles are used as well as the associated modelling assumptions (e.g. proportion of car and ride sharing, value of time, increase in road capacity) are particularly important. 
Figure 4.3.2: Analysed impact of connected and automated transport on transport and urban spaces in simulation studies

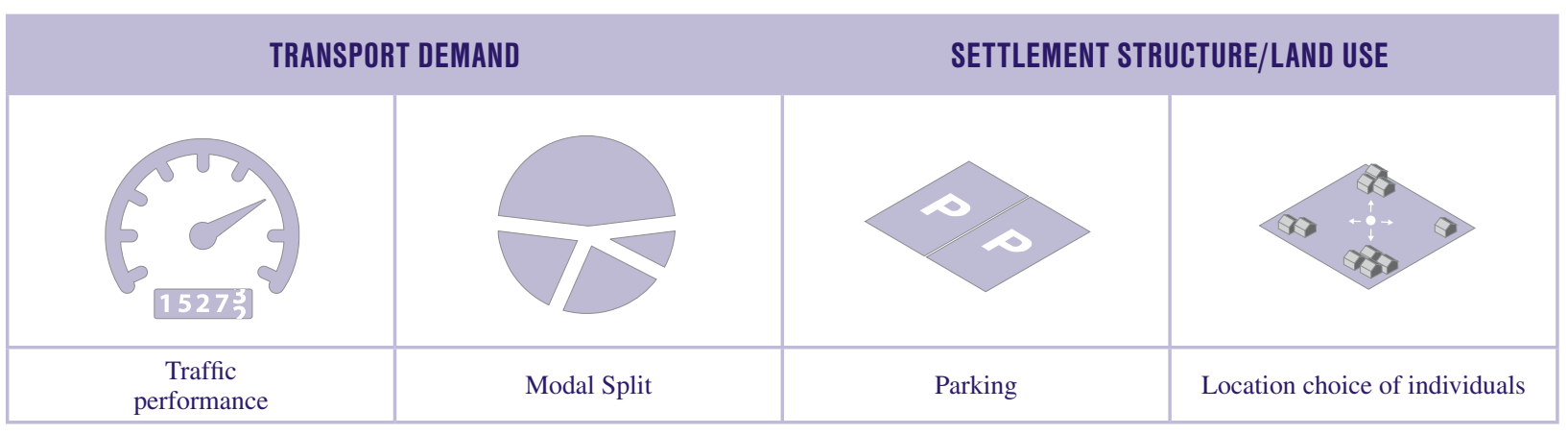

Source: AVENUE21

\subsubsection{IMPACT ON TRANSPORT AND URBAN SPACES}

Present simulations show that there are mainly four aspects that can be differentiated with regard to the impact of CAVs on transport and urban spaces, with the subject of investigations being the demand for transport on the one hand and the influence on settlement structure or land use on the other (Fig. 4.3.2). Further, these studies consider effects on traffic performance, the modal split and parking spaces (Fig. 4.3.1) as well as individuals' and companies' choice of location (Fig. 4.3.3).

\section{TRAFFIC PERFORMANCE}

Regarding traffic performance, it is clear that private automated vehicles are overwhelmingly accompanied by a rise in the number of kilometres driven due to shifts from other modes of transport, with traffic performance growing by $15 \%$ to $59 \%$ when it is assumed that there is a substantial reduction in the value of time (which includes perception of time) and in parking costs and that automated vehicles have a high market share. Even automated vehicles associated with sharing overwhelmingly lead to an increase in the kilometres driven due to shifts from other modes of transport and empty runs. This increase lies between $35 \%$ and $60 \%$ when it is assumed that there is a reduction in the value of time and lower costs for their use, and between $8 \%$ and $89 \%$ when it is assumed that part or all MPT demand is covered by automated vehicles combined with sharing services. Assuming a high proportion of ride sharing results in a $10 \%$ to $25 \%$ reduction in traffic performance.

\section{MODAL SPLIT}

In terms of the modal split, it is evident that private automated vehicles will overwhelmingly lead to a reduction in the proportion of PT, bikes and pedestrians in the modal split (see also the expert opinions and assessments in Chap. 3.4), with substantial reductions being especially clear when a sharp decrease in the value of time and in parking and operating costs is assumed. Even automated vehicles associated with sharing services overwhelmingly lead to a drop in the share of PT passengers, cyclists and pedestrians in the modal split, especially when marked reductions in the value of time and low use costs are assumed. Increases in the proportion of PT use, cycling and walking in the modal split only arise when it is assumed that use costs will be quite high and there will be no private vehicles.

\section{PARKING SPACES}

With regard to a possible reduced need for parking spaces, it is clear that automated vehicles combined with a high proportion of sharing, especially ride sharing, could decrease the overall number of vehicles by approximately $90 \%$, which could also lead to a reduction by as much as $80 \%$ to $90 \%$ in the need for parking spaces. In contrast, private automated vehicles, where sharing only takes place between the members of a single household, might only cut back parking spaces by about $10 \%$. This would also result in a significantly lower reduction in the need for parking spaces and hence fewer potentially usable areas being made available.

\section{LOCATION CHOICE OF INDIVIDUALS AND COMPANIES}

Concerning a change in individuals' and companies' choice of location (Fig. 4.3.3), it becomes apparent that - especially when a reduction in the value of time in the vehicle and an increase in capacity are assumed - private automated vehicles lead to population growth in well-connected suburban/rural areas, i.e. tend to cause sprawling urban growth. In contrast, efficient PT as a result of automation (e.g. connected and automated shuttles for the last mile) leads to population increase in urban areas and hence tends to encourage urbanization processes.

Automated vehicles with sharing services might also curb urban sprawl and suburbanization processes, although it does appear that some demographic groups might move further away from the city centre as a result of the improved transport access. Furthermore, automated vehicles with sharing services could aggravate the deindustrialization trend in cities, i.e. contribute to yet more secondary-sector companies shifting their locations to areas outside of the city. 
Figure 4.3.3: Overview of the impacts of automated vehicles on individuals' location choice

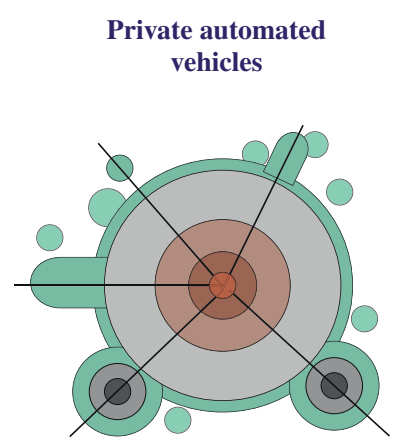

More efficient public transport through automation

Automated vehicles and sharing

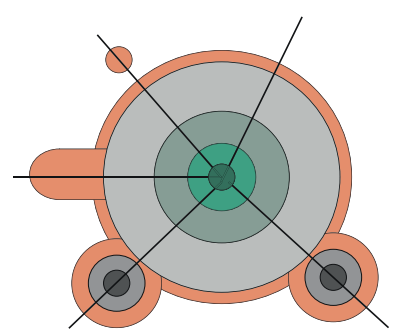

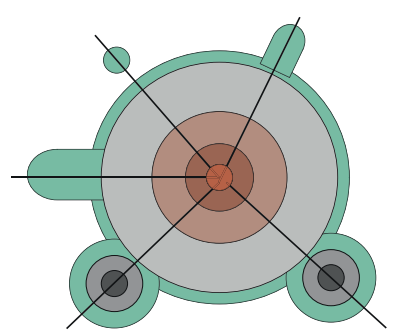

Increase in population size or settlements

Reduction in population size or settlements

Source: AVENUE21 after Kainrath (1997)

As already mentioned, the impact of automated vehicles on transport and urban spaces is thus by and large strongly dependent on the way that automated vehicles are used and on the associated modelling assumptions.

These mainly include:

\section{\% Proportion of ride sharing}

\section{() E Changes in the value of time}

Increase in road capacity

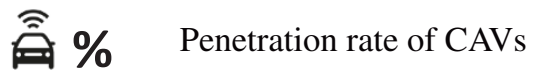

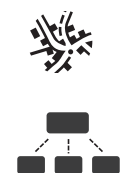

Settlement structure

Model assumptions (e.g. waiting times)

Moreover, the majority of modelling studies that currently exist analyse the comprehensive deployment of highly developed automated vehicles in the distant future. Possible effects in the near future, such as the potential use of automated vehicles only under certain conditions (ODD, Chap. 4.1), e.g. in specific spatial contexts (Beiker 2018: 125; Shladover 2018: 8), have rarely been the subject of scientific research to date. However, they would be of far greater importance for urban and transport planning due to the conceivably quite near-term need for action. It should be added that spatial or general effects of new transport technologies, such as those of automated vehicles, become apparent much sooner than their deployment as a result of decisions, e.g. against constructing new tram lines in Milton Keynes, UK, or in Nashville, USA (Smith 2015, The Economist 2018) being taken with automated vehicles in mind but ahead of their actual deployment.

\subsubsection{CONSEQUENCES FOR URBAN BUDGETS}

Alongside the analysis conducted in the project of automated vehicles' impact on transport demand and settlement structure or land use, the fiscal impacts of automated vehicles, i.e. their effect on public budgets, were also investigated using the example of Austria and specifically Vienna (Mitteregger et al. 2019).

Here it was assumed that as a result of new phenomena in the mobility system - especially the connection and automation but also electrification ${ }^{1}$ of vehicles (in private transport) - the primary effects like possible changes in vehicle ownership, sharing, need for parking spaces, traffic efficiency and need for infrastructure would be fundamental, and would ultimately have a financial impact on public budgets (secondary effects). To analyse the fiscal impacts of connected and automated transport, the primary effects were reviewed on the basis of studies cited in the literature; the resulting secondary effects were then deduced for Austria and finally the significance of the affected revenue and expenditure categories in the budgets of the Austrian provinces and local authorities were presented with a particular focus on Vienna. The budgetary effects of a simultaneous change in PT were not taken into consideration.

\section{OVERVIEW OF POSSIBLE FISCAL IMPACTS²}

Figure 4.3.4 provides an overview of the possible secondary, fiscal effects due to vehicles being connected, automated and electrified, which arise as a result of the primary effects described above. In the area of infrastructure, the public sector may face considerable expenditure for the construction or adaptation of transport infrastructure because of automation and for the installation of charging infrastructure due to electrification. The creation of new or optimization of existing data infrastructure, i.e. digital transport infrastructure as a result of connection (and automation), would mean expenses for the public sector. The possible reduction in the number 


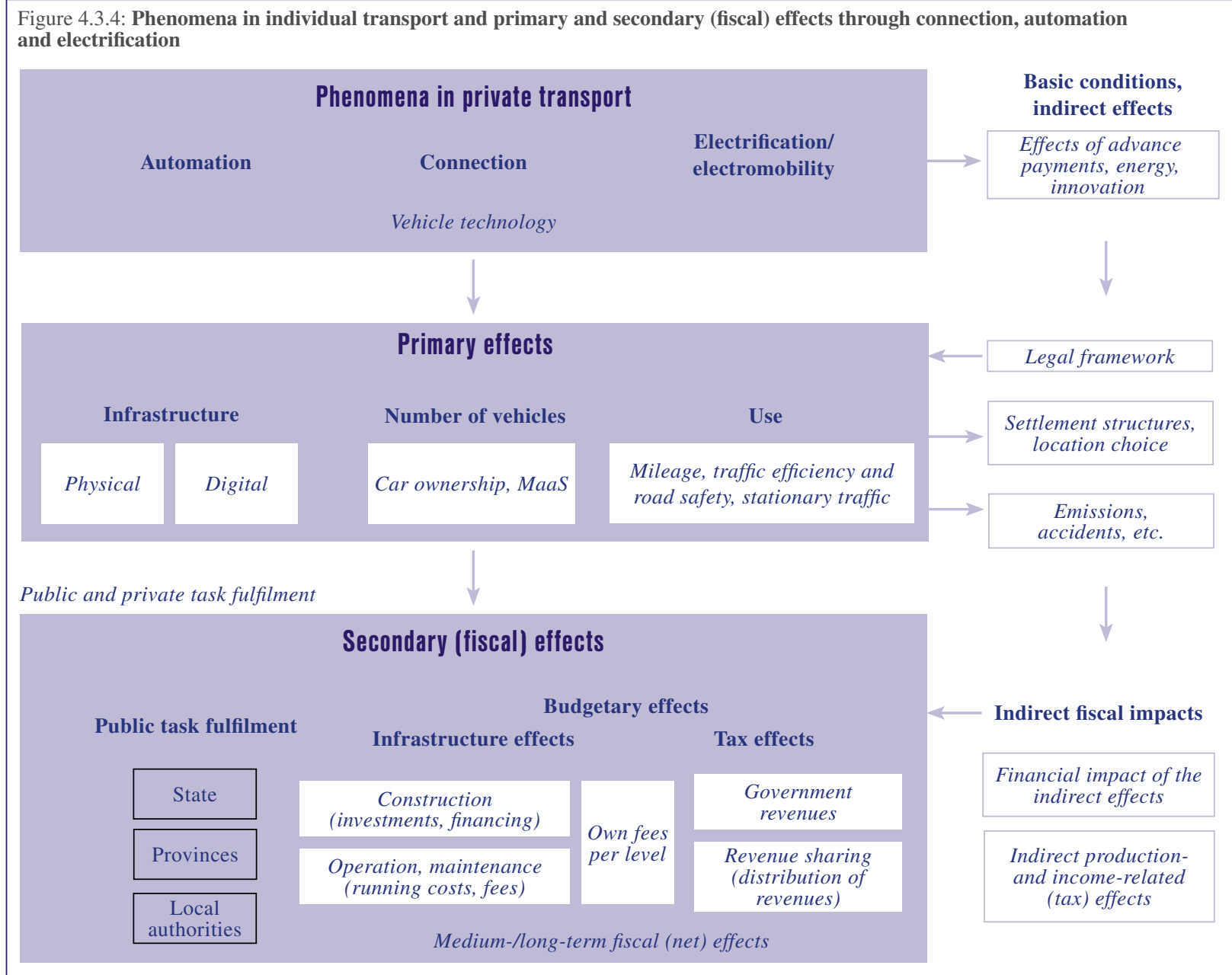

Source: AVENUE21

of vehicles due to automation might lead to reduced revenues from standard fuel consumption tax, engine-related insurance tax and vehicle tax. Furthermore, the reduced need for parking spaces associated with the smaller quantity of vehicles could also result in reduced income from management of parking spaces (parking meter charges or parking fees). In addition, the lower fuel consumption associated with increased traffic efficiency (through connection and automation) could possibly imply a decrease in fuel duty revenue, with this possibly being counteracted by the vehicles being used more (Barnes/Turkel 2017: 21). At all events, however, the electrification of vehicles alone, i.e. electrically powered vehicles, would lead to reduced income from fuel duty, as is already the case in Norway, for example (POLIS 2018: 7). Ultimately, the explicit adherence to traffic laws due to vehicles' automation, which is also relevant in terms of achieving a more efficient flow of traffic, would lead to lower income from traffic fines, such as for speeding or parking violations (Leimenstoll 2017).

In general, it is therefore clear that connected, automated and electrically powered vehicles will mainly affect transport-related revenues (i.e. public sector income) and expenditure in the areas of roadworks, road traffic and telecommunications services.

\section{SIGNIFICANCE OF THE AFFECTED REVENUE AND EXPENDITURE CATEGORIES IN THE BUDGETS OF AUSTRIAN PROVINCES AND LOCAL AUTHORITIES}

Admittedly, it was not possible to judge the exact magnitude of the secondary, fiscal effects described above - in part for want of a more detailed quantitative definition of the primary effects. However, on the basis of the qualitative description of these effects, it was possible to consider the current significance of the affected revenue and expenditure categories for the Austrian provinces and local authorities, with a special focus on Vienna, in order to identify the possible scope of these fiscal impacts. To this end, the secondary, fiscal effects depicted in italics in Figure 4.3.5 were supported with data (where possible). ${ }^{3}$

\section{REVENUES}

In Austria, the aforementioned transport-related sources of income (federal government revenues), such as fuel duty, are generally levied by the state. The provinces and local authorities then receive a share of those revenues, with the amount being defined by the distribution rule as 
Figure 4.3.5: Overview of the primary effects of connection, automation and electrification as well as the resulting possible fiscal impacts

\begin{tabular}{|c|c|c|c|}
\hline \multirow[t]{2}{*}{ PHENOMENON } & \multirow[t]{2}{*}{ PRIMARY EFFECT } & \multicolumn{2}{|c|}{ SECONDARY, FISCAL EFFECT } \\
\hline & & Income & Expenditure \\
\hline Automation & \multirow{3}{*}{ Infrastructure } & & Transport infrastructure \\
\hline Connection & & & $\begin{array}{c}\text { Data infrastructure } \\
\text { (digital transport infrastructure) }\end{array}$ \\
\hline Electrification & & Fuel duty & $\begin{array}{l}\text { Charging infrastructure, } \\
\text { electrical grid }\end{array}$ \\
\hline \multirow{3}{*}{ Automation } & \multirow{3}{*}{$\begin{array}{l}\text { Number of vehicles } \\
\text { (reduction in privately } \\
\text { owned cars) }\end{array}$} & Standard fuel consumption tax & \\
\hline & & Engine-related insurance tax & \\
\hline & & Vehicle tax & \\
\hline $\begin{array}{l}\text { Automation } \\
\text { Connection and } \\
\text { automation }\end{array}$ & $\begin{array}{c}\text { Use } \\
\text { Need for parking spaces } \\
\text { Traffic efficiency and road } \\
\text { safety }\end{array}$ & $\begin{array}{c}\text { Managing parking spaces } \\
\text { (parking meter charges/fees) } \\
\text { Parking/traffic fines } \\
\text { Fuel duty }\end{array}$ & Parking infrastructure \\
\hline
\end{tabular}

outlined in the Fiscal Equalization Act (Finanzausgleichgesetz; BMF 2018, Bröthaler et al. 2017).

Looking at the federal government revenues (Table 4.3.1), it becomes clear that transport-related revenues like fuel duty, standard fuel consumption tax, engine-related insurance tax, vehicle tax and insurance tax change as a result of shifting to connected, automated and/or electrically powered vehicles. Considering this effect is crucial bearing in mind that these revenues amounted to some $€ 8.5$ billion in 2016 or $10.7 \%$ of the total federal government revenues that year, for example. At $5.6 \%$ and $3.0 \%$ respectively, fuel duty and engine-related insurance tax constitute the largest proportion of these revenues. Over the course of time, the proportion of transport-related income in the federal government revenues is relatively stable.

Turning to the income of the provinces and local authorities after applying the distribution formula for the federal government revenues (Fig. 4.3.2), it becomes apparent that the shares of transport-related revenues (although not earmarked) in 2017 amounted to $4.0 \%$ and $3.7 \%$ of total revenues for the provinces (excluding Vienna) and for the local authorities (excluding Vienna) respectively. For Vienna, the share of transport-related revenues totals $€ 631$ million or $4.3 \%$. Revenues from parking meters and parking fines, which would also be subject to change as a result of connected, automated and electrically powered vehicles, constituted $€ 115$ million and $€ 82$ million respectively in 2017; taken together, this amounts to some $1.4 \%$ of Vienna's total revenue.

\section{EXPENDITURE}

Looking at the expenditure of the provinces (excluding Vienna) and the local authorities (excluding Vienna) in Table 4.3.2, the expenditure - which will possibly be different as a result of the advent of connected, automated and electrically powered vehicles - for roadworks and road traffic in 2017 amounted to $3.7 \%$ (provinces without

Table 4.3.1: Amount of federal government revenues in 2007 and 2017 in millions of euros and in per cent

\begin{tabular}{|c|c|c|c|c|}
\hline FEDERAL GOVERNMENT REVENUES & $\begin{array}{l}\text { 2007: } \\
\text { € MILLION }\end{array}$ & $\begin{array}{l}\text { 2017: } \\
\text { € MILLION }\end{array}$ & $\%$ P.A & $\begin{array}{c}\text { 2017: } \\
\%\end{array}$ \\
\hline Fuel duty & 3,689 & 4,436 & 1.9 & 5.6 \\
\hline Standard fuel consumption tax & 456 & 469 & 0.3 & 0.6 \\
\hline Engine-related insurance tax & 1,410 & 2,389 & 5.4 & 3 \\
\hline Vehicle tax & 1,115 & 38 & -10.4 & 0 \\
\hline Insurance tax & 993 & 1,128 & 1.3 & 1.4 \\
\hline Total transport-related revenues & 6,663 & 8,461 & 2.4 & 10.7 \\
\hline Income tax & 30,516 & 39,269 & 2.6 & 49.5 \\
\hline VAT & 19,212 & 25,519 & 2.9 & 32.2 \\
\hline Other federal government revenues & 3,870 & 6,015 & 4.5 & 7.6 \\
\hline Total revenues & 60,261 & 79,264 & 2.8 & 100 \\
\hline
\end{tabular}


Table 4.3.2: Income of the provinces and local authorities from taxes and other sources of revenue in 2017 in millions of euros and proportion of total revenue in per cent

\begin{tabular}{|c|c|c|c|c|c|c|}
\hline REVENUE 2017 & $\begin{array}{c}\text { Provinces } \\
\text { without } \\
\text { Vienna }\end{array}$ & $\begin{array}{l}\text { LLIONS OF E } \\
\text { Local } \\
\text { authorities } \\
\text { without } \\
\text { Vienna }\end{array}$ & Vienna & $\begin{array}{c}\text { Provinces } \\
\text { without } \\
\text { Vienna }\end{array}$ & $\begin{array}{l}\text { IN PER CENT } \\
\text { Local } \\
\text { authorities } \\
\text { without } \\
\text { Vienna }\end{array}$ & Vienna \\
\hline Total transport-related revenue & 1,369 & 741 & 631 & 4.0 & 3.7 & 4.3 \\
\hline Profits tax & 6,344 & 3,432 & 2,922 & 18.4 & 17.1 & 19.9 \\
\hline VAT & 4,232 & 2,308 & 1,713 & 12.3 & 11.5 & 11.7 \\
\hline Other government revenues & 1,298 & 1,057 & 793 & 3.8 & 5.3 & 5.4 \\
\hline Income tax share of federal govt. revenues & 13,244 & 7,537 & 6,059 & 38.4 & 37.7 & 41.2 \\
\hline Parking meter charges incl. fees & & 70 & 115 & & 0.3 & 0.8 \\
\hline Other local revenues & 679 & 3,448 & 1,294 & 2.0 & 17.2 & 8.8 \\
\hline Total revenue & 13,923 & 11,055 & 7,468 & 40.4 & 55.2 & 50.8 \\
\hline Parking/traffic fines (earmarked) & 50 & 70 & 82 & 0.1 & 0.4 & 0.6 \\
\hline Other steady revenue & 15,789 & 5,362 & 4,261 & 45.8 & 26.8 & 29.0 \\
\hline Revenues from assets & 4,705 & 3,526 & 2,882 & 13.7 & 17.6 & 19.6 \\
\hline Total revenue & 34,466 & 20,013 & 14,693 & 100.0 & 100.0 & 100.0 \\
\hline
\end{tabular}

Source: AVENUE21 after public accounts, Statistics Austria (2019a)

Vienna) and $7.8 \%$ (local authorities without Vienna) of total expenditure. For Vienna, the sum is €261 million or a share of $1.8 \%$ of total expenditure. Over the past ten years, it is apparent that the share of expenditure for roads in Vienna has remained at a similar level, whereas it has slightly declined in the provinces (excluding Vienna) and in the local authorities (excluding Vienna).

Consequently, the revenue and expenditure categories affected by the introduction of connected, automated and electrically powered vehicles constitute a not insignificant proportion of total revenues and total expenditure in Austrian provinces and local authorities, especially in Vienna.

1 The electrification of vehicles (changing to electric propulsion systems) was included, although this is not necessarily linked to automation. The simultaneity of the two phenomena is, however, frequently emphasized in the literature (e.g. Bormann et al. 2018).

2 This section summarizes the findings of "Shared, Automated, Electric: The Fiscal Effects of the Holy Trinity" (Mitteregger et al. 2019). Expanding the analysis of CAT's possible effects to include fiscal impacts on local authorities would not have been pos- sible without the co-authorship of Johann Bröthaler (Department of Public Finance and Infrastructure Policy at the TU Wien).

3 Here, it should be borne in mind that identifying the source of revenue is possible to a relatively precise extent, but that the revenues are not earmarked at this time. In terms of expenditure, in contrast, identifying funds is in part only possible to a rough extent (especially with regard to digitalization and electricity supply/charging infrastructure) due to budgetary categorization, the different ways in which expenditure is booked and institutional conditions (areas of responsibility). Furthermore, the empirical account is limited to the budgets of the provinces and local authorities as regional authorities (without outsourced or extrabudgetary units).

Table 4.3.3: Expenditure of provinces and local authorities on roads and public transport in 2017 in millions of euros

\begin{tabular}{|c|c|c|c|c|c|c|}
\hline EXPENDITURE 2017 & $\begin{array}{c}\text { IN } \\
\text { Provinces } \\
\text { without } \\
\text { Vienna }\end{array}$ & $\begin{array}{l}\text { LLIONS OF E } \\
\text { Local } \\
\text { authorities } \\
\text { without } \\
\text { Vienna }\end{array}$ & Vienna & $\begin{array}{c}\text { Provinces } \\
\text { without } \\
\text { Vienna }\end{array}$ & $\begin{array}{l}\text { IN PER CENT } \\
\text { Local } \\
\text { authorities } \\
\text { without } \\
\text { Vienna }\end{array}$ & Vienna \\
\hline Roads & 1,283 & 1,783 & 261 & 3.7 & 7.8 & 1.8 \\
\hline Public transport & 580 & 161 & 774 & 1.7 & 0.7 & 5.3 \\
\hline Other expenses & 32,639 & 21,007 & 13,658 & 94.6 & 91.5 & 93.0 \\
\hline Total expenditure & 34,502 & 22,952 & 14,693 & 100.0 & 100.0 & 100.0 \\
\hline
\end{tabular}


Figure 4.3.6: Impacts of automated vehicles in SAE Level 5

\begin{tabular}{|c|c|}
\hline \multicolumn{2}{|c|}{ TRAVEL TIME } \\
\hline \multicolumn{2}{|c|}{ Reduced perception of time } \\
\hline$r$ & $\begin{array}{l}\text { - higher productivity (carrying out different } \\
\text { activities) } \\
\text { - higher driving comfort (optimized longitudinal } \\
\text { and lateral acceleration, avoidance of driving- } \\
\text { related stress) }\end{array}$ \\
\hline 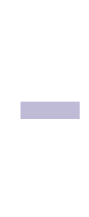 & $\begin{array}{l}\text { - passengers in CAVs more likely to suffer from } \\
\text { travel or motion sickness } \\
\text { - unfamiliar or lacking experience in dealing with } \\
\text { CAVs } \\
\text { - shorter distances between vehicles }\end{array}$ \\
\hline \multicolumn{2}{|c|}{ Reduced travel time } \\
\hline L & $\begin{array}{l}\text { - loss of car parking traffic } \\
\text { - elimination of parking processes and journeys to } \\
\text { the car park/destination }\end{array}$ \\
\hline \multicolumn{2}{|c|}{ Reliable travel time } \\
\hline 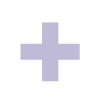 & $\begin{array}{l}\text { - } \text { almost constant speeds } \\
\text { - } \quad \text { reliable and predictable routes }\end{array}$ \\
\hline
\end{tabular}

\begin{tabular}{|l|l|}
\hline SAFETY \\
\hline Increased traffic safety \\
\hline & reduced driver-related causes of accidents \\
\hline & $\begin{array}{l}\text { unclear during the transition period and in mixed } \\
\text { traffic }\end{array}$ \\
\hline Accidents & \\
\hline$-70 \%$ to $-95 \%$ & \\
\hline & \\
\hline Low cyber security \\
\hline
\end{tabular}

Source: BMVIT (2016b)

\begin{tabular}{|c|c|}
\hline \multicolumn{2}{|l|}{ COSTS } \\
\hline \multicolumn{2}{|c|}{ Reduced operating costs } \\
\hline r & $\begin{array}{l}\text { - more fuel-efficient and lighter vehicles } \\
\text { - fuel-saving vehicle styles } \\
\text { - lower costs for vehicle insurance } \\
\text { - personnel cost savings in PT } \\
\text { - } \text { reduced wear costs (e.g. for tyres) in PT }\end{array}$ \\
\hline \multicolumn{2}{|c|}{ Higher purchase costs } \\
\hline$\sqrt{1}$ & - expensively built sensors and software components \\
\hline$\square$ & $\begin{array}{l}\text { elimination of driver-related equipment inside the } \\
\text { vehicle (steering wheel, brake and accelerator } \\
\text { pedals) }\end{array}$ \\
\hline \multicolumn{2}{|c|}{ Costs per passenger kilometre (incl. amortization) } \\
\hline \multicolumn{2}{|c|}{$-16 \%$ to $+4 \%$} \\
\hline \multicolumn{2}{|c|}{ Sinking parking costs } \\
\hline 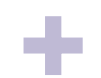 & $\begin{array}{l}\text { parking in cheaper areas or areas without parking } \\
\text { charges }\end{array}$ \\
\hline
\end{tabular}

\begin{tabular}{|c|c|}
\hline ROAD & PACIT \\
\hline Increa & d road \\
\hline 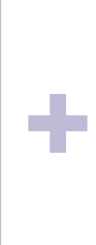 & $\begin{array}{ll}\cdot & \mathrm{h} \\
& \mathrm{cl} \\
\cdot & \mathrm{fe} \\
\cdot & \mathrm{n} \\
\cdot & \mathrm{sh}\end{array}$ \\
\hline Road & oacity \\
\hline$+50 \%$ & $+414 \%$ \\
\hline
\end{tabular}

Source: Van den Berg/Verhoef (2016), Bösch (2016)

\begin{tabular}{|l|}
\hline NEW USER GROUPS \\
\begin{tabular}{|l|l|}
\hline Tapping into new user groups \\
\hline $\begin{array}{l}\text { lower demands on drivers/passengers (no driving } \\
\text { licence necessary) }\end{array}$ \\
\hline People with limited mobility in Austria \\
\hline $10 \%$ to $38 \%$ \\
\hline
\end{tabular} \\
\hline
\end{tabular}




\begin{tabular}{|c|c|}
\hline \multicolumn{2}{|c|}{ ENERGY AND THE ENVIRONMENT } \\
\hline \multicolumn{2}{|c|}{ Energy efficiency (fuel savings) } \\
\hline \multicolumn{2}{|c|}{$-11 \%$ to $-47 \%$} \\
\hline \multicolumn{2}{|c|}{ Emissions } \\
\hline $\mathrm{CO}$ & $-32 \%$ to $-61 \%$ \\
\hline $\mathrm{CO}_{2}$ & $-61 \%$ to $+105 \%$ \\
\hline $\mathrm{NO}_{x}$ & $-2 \%$ to $-18 \%$ \\
\hline \multicolumn{2}{|c|}{$\begin{array}{l}\text { There are occasional studies concerning automated vehicles' } \\
\text { impact on energy and the environment. However, even here the } \\
\text { effects vary widely. Further research is required, especially in } \\
\text { terms of the effects on traffic and mobility. }\end{array}$} \\
\hline
\end{tabular}

Source: Fagnant et al. (2015), Milakis et al. (2017), Wadud et al. (2016)

\begin{tabular}{|c|c|}
\hline \multicolumn{2}{|c|}{ ECONOMY AND PUBLIC FINANCES } \\
\hline Profit per vehicle & $€ 2,960$ to $€ 3,900$ \\
\hline Value added & $+30 \%$ \\
\hline Loss of taxes/revenue & Current significance in Austria \\
\hline $\begin{array}{l}\text { Standardized consumption } \\
\text { tax }\end{array}$ & $€ 2,960$ to $€ 3,900$ \\
\hline $\begin{array}{l}\text { Engine-related insurance } \\
\text { tax }\end{array}$ & $+30 \%$ \\
\hline Parking meter charges & $€ 2,960$ to $€ 3,900$ \\
\hline Parking/traffic fines & $+30 \%$ \\
\hline $\begin{array}{l}\text { There have been barely any s } \\
\text { demonstrate the current signi } \\
\text { income sources for the public } \\
\text { be is, however, largely uncert } \\
\text { described above. }\end{array}$ & $\begin{array}{l}\text { lies in this area. At most, studies } \\
\text { ance of the possible loss of } \\
\text { ector; just how great this loss will } \\
\text { and dependent on the impacts }\end{array}$ \\
\hline
\end{tabular}

Source: Clements/Kockelman (2017), Fagnant/Kockelman (2015), Mitteregger et al. (2019) 
4.4

\section{AUTOMATED DRIVABILITY: A NUANCED PICTURE OF THE SPATIAL DEPLOYMENT OF CONNECTED AND AUTOMATED VEHICLES}

Insight into the dissertation of Aggelos Soteropoulos

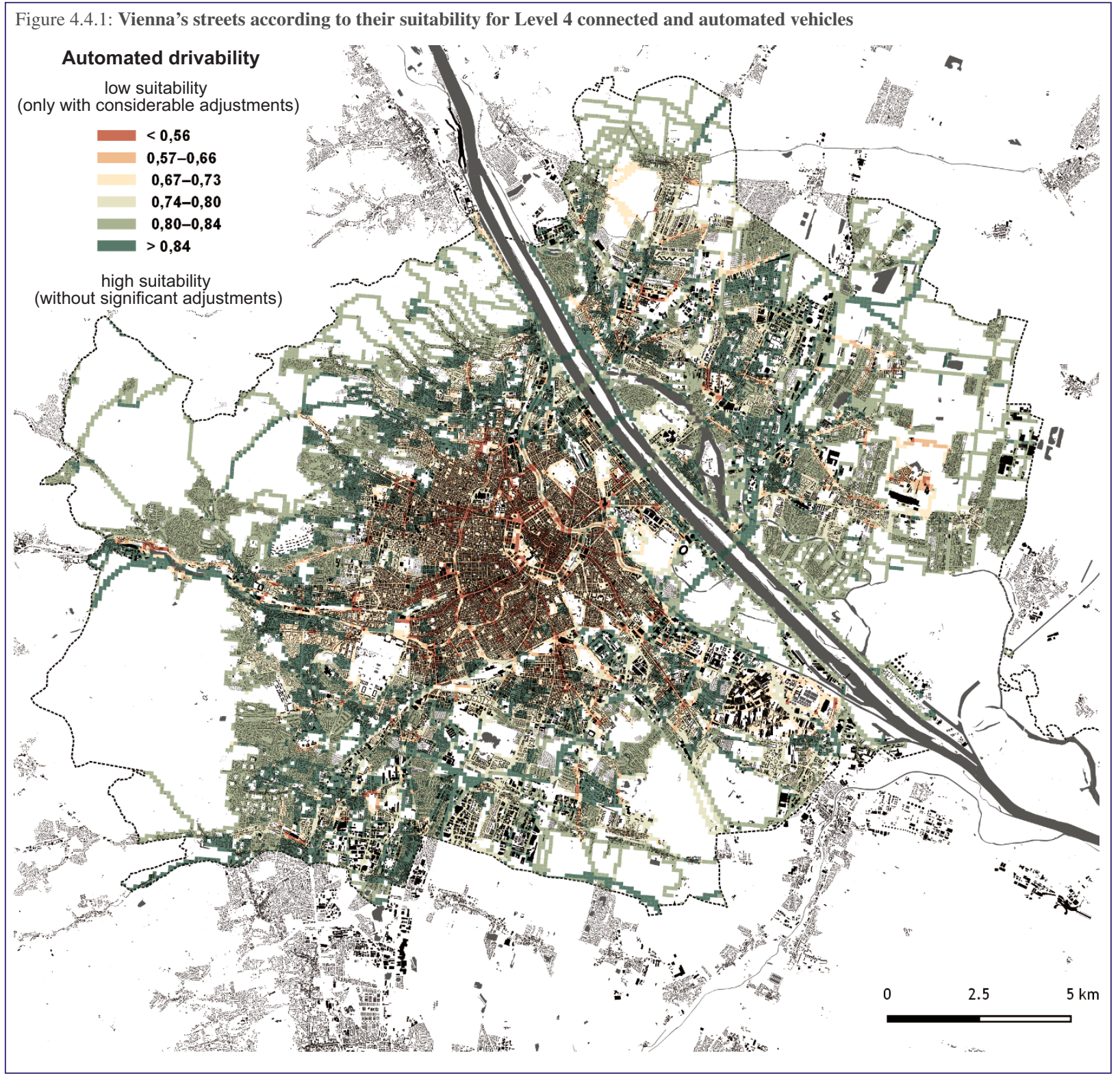

Source: AVENUE2

As explained in Chapter 4.3, simulations and forecasts on the use of CAT only take into account the qualitative differences between streetscapes to a limited extent. Thus, it is assumed that e.g. motorways or special areas constitute "easier" automation tasks and consequently automated driving systems (SAE International 2018 does not yet define any connection here) will be used there sooner (see also Chap. 4.1). However, beyond this broad comparison, a nuanced view that includes the characteristics of the streetscapes and environmental conditions in these two categories is lacking. The term operational design domain (ODD) was introduced 


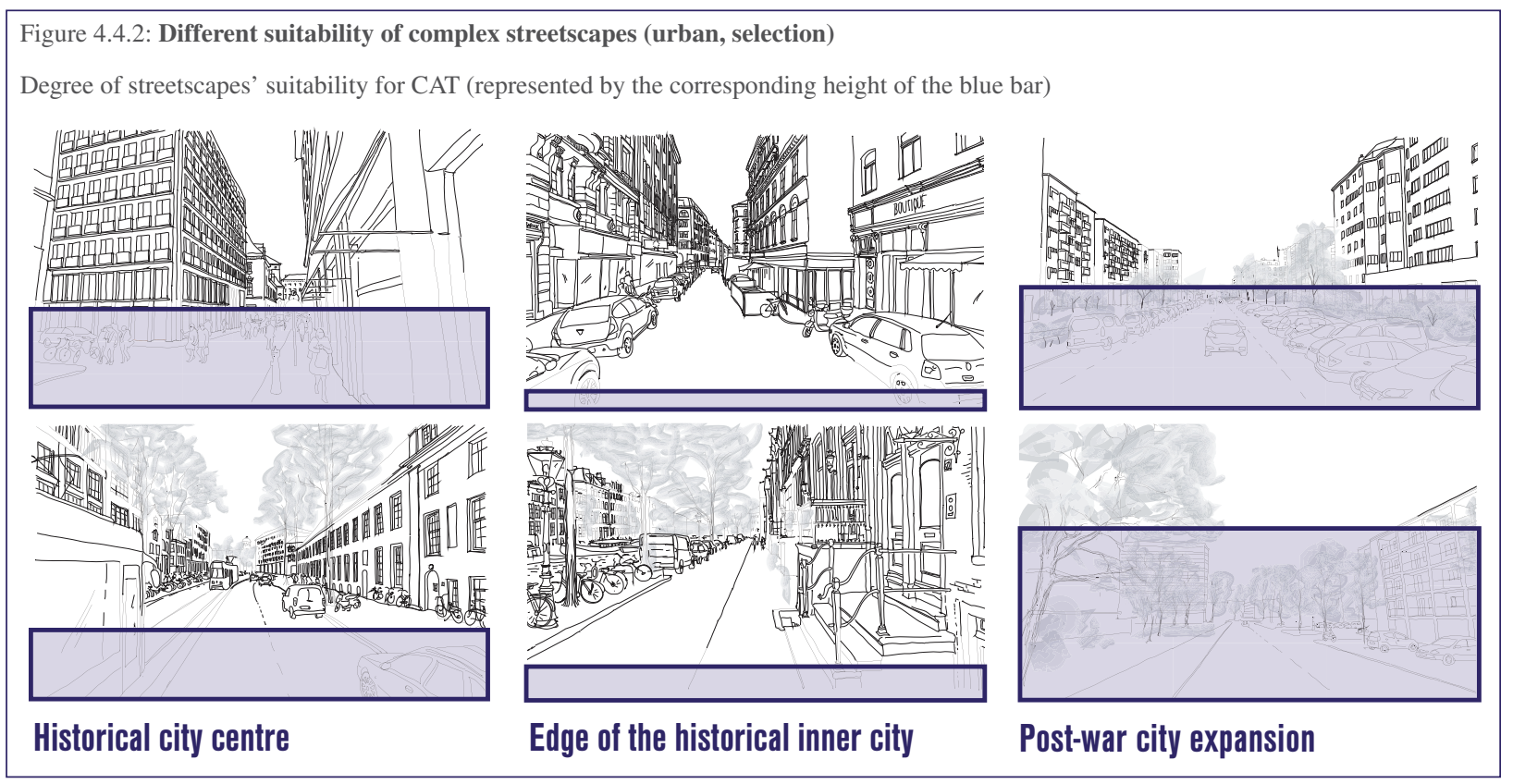

Source: AVENUE21

to the famous SAE levels with their revision in 2016 to convey the range of complexity in environments for vehicle automation (SAE International 2018: 14). For example, an automated driving system can only function at low speeds, in good weather and during the day (Fraade-Blanar et al. 2018: 13). These limitations would correspond to the ODD for which the system was designed.

In the AVENUE21 research project, a first step towards developing an index of automated drivability was taken in order to take into consideration in a more nuanced way the demands on automated driving systems that depend directly on the complexity of the ODD (see Fig. 4.4.3). The starting point for this index was the fact that certain road contexts increase the demands on automated driving systems (Metz 2018: 3). This results in particular from the way they function: automated driving systems have to perceive their surroundings using various sensors, map it using the sensor data (perception and cognition), make the corresponding driving decisions (planning and control) and communicate them to the passengers and other road users (human-machine interaction; Ritz 2018: 41). Different deployment environments and associated conditions can complicate these processes, for example when a large number of different road users have to be recognized and their future movements predicted or anticipated (Shladover 2018: 31).

\section{EUROPEAN CITIES: VARIETY OF STREETSCAPES}

Especially in European cities, there is a wide variety of streetscapes, which differ greatly in terms of their structural and infrastructural appearance, the surrounding architecture and the range of road users and hence make very different demands on automated driving systems (see Fig. 4.4.2). Streetscapes also have different functions (connection or access function) and congestion levels or traffic density (FGSV 2006: 8; Marshall 2005: 50). As points of connection between roads, junctions are also diverse (right of way for traffic coming from the right, priority traffic signs, light signals, roundabouts, etc.) and depend on the characteristics of the connecting roads (FGSV 2006: 54).

Figure 4.4.3: Basic relationship between the automated driving system and the ODD

On streets with lower complexity, automated driving systems can predict the processes they need to carry out more precisely and more easily (left). In contrast, streets with high complexity complicate the precision of this prediction (right).

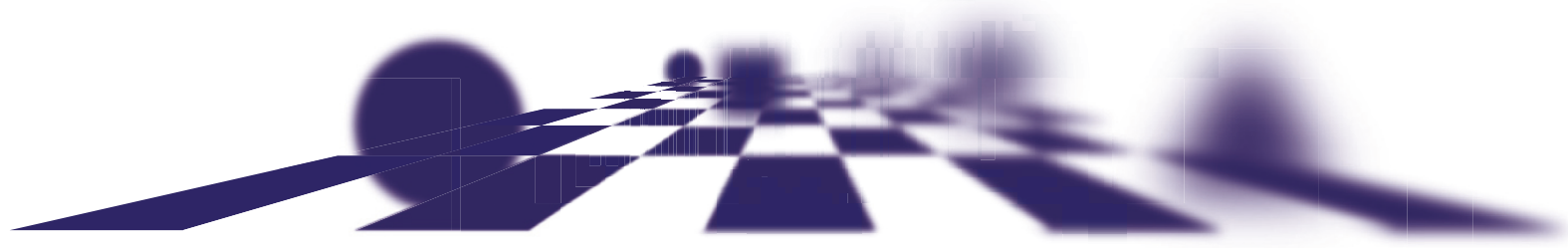


FACTORS IN STREETSCAPES' SUITABILITY FOR THE USE OF CONNECTED AND AUTOMATED VEHICLES: AUTOMATED DRIVABILITY

Proceeding from these points, factors were developed that identify the suitability of streets or roads for the use of CAVs - i.e. their automated drivability - and hence also define the spatially nuanced use of CAT. These factors comprise (see Fig. 4.4.4):

1 the number of objects in the streetscape,

2 the variety of objects in the streetscape,

3 the stability of the ODD,

4 the permitted speed range and

5 the condition of the infrastructure.

\section{ASSESSMENT OF AUTOMATED DRIVABILITY: VIENNA AS A CASE STUDY}

Using the city of Vienna as a case study, example criteria were derived and combined in light of the developed factors and dependent on the availability of data; these criteria map as well as possible the developed factors and hence streetscapes' suitability for the functional deployment of automated driving systems (see Fig. 4.4.5). The criteria used are an attempt to convey the heterogeneity of various streetscapes in their location in the city. Figure 4.4.1 shows the assessment of automated drivability using the example of the city of Vienna. It makes clear that cities are by no means homogeneous spaces when it comes to the possibilities of deploying CAVs. Rather, the derived criteria reveal that a spatially selective deployment of CAVs is probable due to the differing suitability of streetscapes in cities and that the advantages and disadvantages of the deployment of CAVs in the long transition period will be distributed unequally.

One consequence of this heterogeneity is a shift in locations' popularity due to the accessibility with CAVs of passenger and freight transport. It is noticeable that more car-friendly peripheral areas of the city (which are shown in green in Fig. 4.4.1) tend to have an advantage over older, largely more complex neighbourhoods in the city centre. While the former could be accessed by CAVs without (considerable) adjustments and presumably relatively soon, the deployment of CAVs in the latter would only be conceivable if considerable adjustments were made to the streetscape (built infrastructure), speeds were generally reduced and the area were upgraded with digital infrastructure (shown in red) yet for such changes there are no standards whatsoever at this time. Furthermore, it is clear that European
Figure 4.4.4: Short description of the developed factors

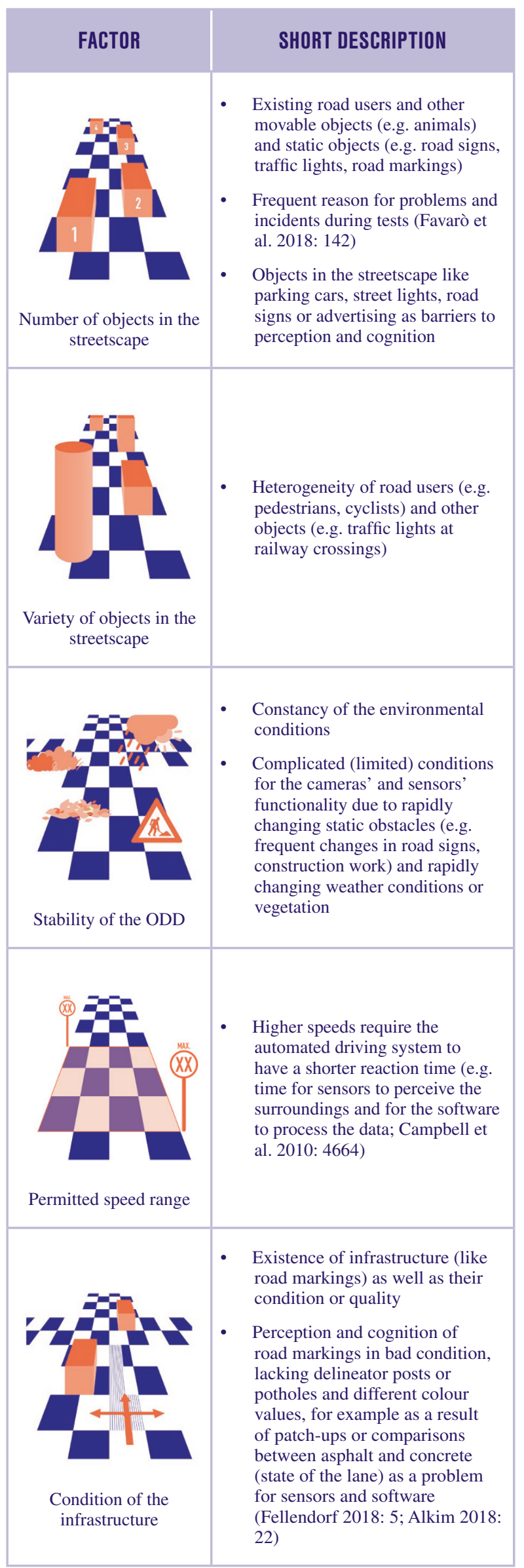


Figure 4.4.5: Overview of the derived criteria for mapping automated drivability using the example of Vienna (excerpt)

\section{NUMBER OF OBJECTS IN THE STREETSCAPE \\ NUMBER AND VARIETY OF OBJECTS IN THE STREETSCAPE}

Existence of a pedestrian zone or shared space

Overwhelmingly residential area type

$\Rightarrow \mid+$

Average lane width

PERMITTED SPEED RANGE

Reduced speed in the section of the road
(H) Number of PT stops

3 Number of traffic lights

STABILITY OF THE OPERATIONAL DESIGN DOMAIN

Existence of vegetation (trees, bushes ...)
VARIETY OF OBJECTS IN THE STREETSCAPE

Existence of cycling infrastructure in the lane

\section{CONDITION OF THE \\ INFRASTRUCTURE}

Difference in road surfaces

cities, which frequently have historical, pedestrian-oriented centres with narrow streets, cannot accommodate motorized and connected transport. Transportation network companies like Uber or Lyft are now reacting to this by moving their services to two-wheeled vehicles in such areas.

This assessment for Vienna has provided an initial overview of the suitability of road environments for the deployment of CAVs. With more data, the analysis can be differentiated. Nevertheless, in light of the developed index, the mapping of Vienna's automated drivability (Fig. 4.4.1) offers an insight into the areas that can be accessed by CAT without (considerable) adjustments and that are in no way equally distributed across the city. In addition, a social space analysis could identify which social groups live on the green or red-marked streets and what mobility styles are dominant there. This knowledge is of fundamental importance for policy and planning in order to develop nuanced measures. 
4.5

\section{TRANSITION MANAGEMENT IN PIONEERING REGIONS AROUND THE GLOBE}

In the context of the effects of CAM on cities and urban regions, so-called pioneering regions will be described. This means cities or urban regions that are actively researching, planning and developing as well as testing and demonstrating CAVs and CAM and that are pushing to implement $\mathrm{CAM}$ in view of regional challenges.

The focus of this chapter is on the challenges that cities and urban regions hope to address by deploying CAVs, and the transition initiatives that make cities and urban regions co-producers in the development of CAVs.

\section{SELECTION OF THE PIONEERING REGIONS}

In the course of our research, some 20 urban regions were chosen, analysed and compared. After helpful discussions with experts, five of them were selected as pioneering regions: they lie in the USA (San Francisco), in the UK (the metropolitan region of London), in Sweden (Gothenburg) and in Japan (the metropolitan region of Tokyo). The fifth pioneering region chosen was the city state of Singapore (see Fig. 4.5.1). The aim of the study was to review as broad a spectrum of different reference regions as possible which reveal relevant visions of the future and development possibilities in which transition initiatives are visible in strategies and programmes and which have already found recognition for their contributions to the global discourse around CAT.

\section{THE FOUR ANALYTICAL CATEGORIES}

To analyse these pioneering regions, the theoretical frameworks of transition theory (Rotmans et al. 2001, Kemp/Loorbach 2003, Geels 2005) and the multi-level perspective (MLP; Geels 2010) were applied. The heuristic methods of MLP view system transitions as relational processes which, through the interaction between the developments, result in three dimensions (Rotmans et al. 2001):

- The dimension "landscape" covers local or translocal aspects of a city/region, such as the effects of demographic change.

- The dimension "regime" includes a country's prevalent practices, regulations, etc.

- The dimension "niche" encompasses "protected spaces" like research laboratories, start-ups, etc., which experiment with innovations.

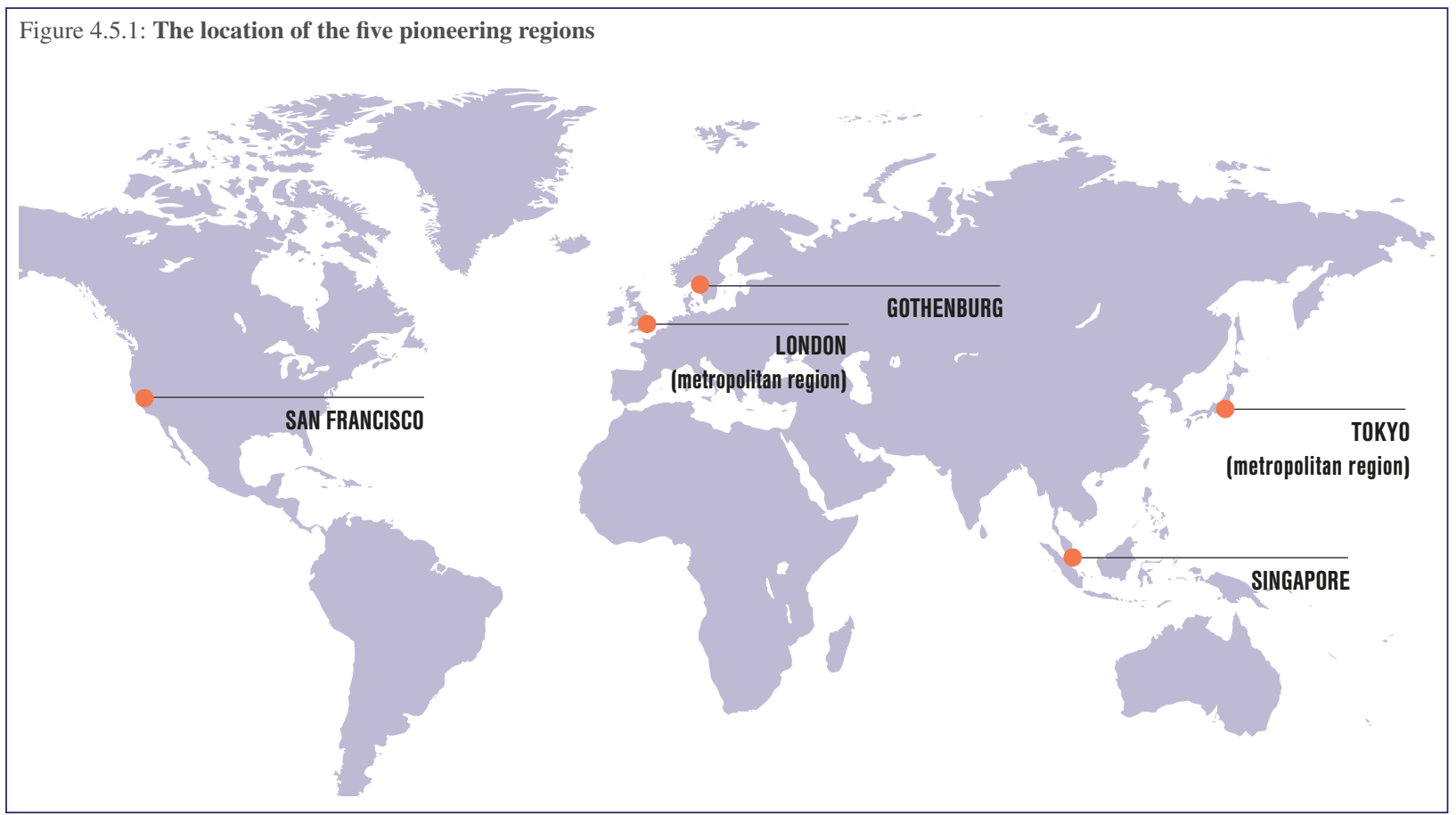

Source: AVENUE21 
Based on these two theories, four analytical criteria were developed for the analysis and comparative evaluation of the pioneering regions:

1 "Drivers" refer on the one hand to the pressure to act resulting from the social and ecological challenges ("landscape"), and on the other to the pressure from the "niche".

2 "Innovation networks" refer to the key actors and alliances involved, which jointly plan and initiate progress and change ("regime" and "niche").

3 "Development narratives" refer to visions and models that arise in corporative and political negotiation processes (see Chap. 4.6).

4

"Transition initiatives" are associated strategies and programmes that are intended to provide orientation for joint action (e.g. in the form of road maps).

Research questions were formulated for each of the four analytical categories. With all of these questions, the focus was on the interplay of CAM strategies and the long-term plans for urban development and transport in the respective pioneering region (see Fig. 4.5.2).

\section{SUMMARY OF THE RESULTS: CONCEPTION OF CONNECTED AND AUTOMATED MOBILITY FROM THE PERSPECTIVE OF CITIES/URBAN REGIONS}

The approaches taken by the five selected pioneering regions (cities/urban regions) are summarized below with reference to the four analytical categories: (1) drivers, (2) innovation networks, (3) development narratives and (4) transition initiatives.

\section{SAN FRANCISCO (USA)}

Drivers: The current urban challenges in San Francisco are an acute housing shortage, a fragmented public transport system, unequal growth patterns between the districts, a growing evening economy and limited mobility options, especially for low-income households, seniors and people with disabilities (SFMTA 2016a, 2016b: 1; SFMTA 2018). The tech giants of Silicon Valley in particular are eager to be allowed to test their technologies on the streets of San Francisco.

Innovation networks: The San Francisco Municipal Transportation Agency (SFMTA) is the main actor supporting automated transport in San Francisco. A meeting place, an agency and an idea incubator called Smart City Institute (also known as Superpublic) have been set up (ATCMTD, City of San Francisco 2016, SEE 14). With the "Community-Guided Engagement Plan", a framework has been created to bring about different kinds of cooperation and alliance between various sectors and actors (i.e. cross-sector collaboration). In addition, the city has entered into an alliance with the World Economic Forum with a special focus on CAM.

Development narratives: The first two CAM narratives mainly refer to safety ("Vision Zero SF") and improved mobility options for low-income households ("Transportation is the greatest equalizer of all"). CAM is addressed directly by the third narrative, which conceptualizes a medium- and long-term vision of the future that revolves around shared, electric, connected and automated vehicles (SECAVs).

Transition initiatives: The home of the sharing economy has set itself the task of introducing, testing and later incorporating a large quantity of shared forms of mobility in the wide range of mobility services available. In order to achieve this long-term goal, there is considerable reliance on the deployment of CAVs. The transition to SE-

Figure 4.5.2: Categories and main research questions in the context of analysing the pioneering regions

\begin{tabular}{|c|c|}
\hline ANALYTICAL CATEGORIES & RESEARCH QUESTIONS \\
\hline $\begin{array}{r}\text { Drivers: } \\
\text { challenges and expectations }\end{array}$ & $\begin{array}{l}\text { - What induces cities/regions (policymakers, administration) to invest in CAM? } \\
\text { - What drivers emerge due to the pressure to act from the "landscape" or "niche"? }\end{array}$ \\
\hline $\begin{array}{l}\text { Innovation networks: } \\
\text { actors and cooperation }\end{array}$ & $\begin{array}{l}\text { - Who are the relevant actors in a city/urban region who will advocate the introduction and } \\
\text { distribution of CAVs? } \\
\text { - What types of cooperation are there? What alliances have been formed? } \\
\text { - What steps have been taken to achieve progress and change towards CAM? }\end{array}$ \\
\hline $\begin{array}{r}\text { Development narratives: } \\
\text { visions and models }\end{array}$ & $\begin{array}{l}\text { What visions of the future have been jointly formulated? What strategic goals and models } \\
\text { have been derived from them? } \\
\text { - What narratives are preferred to make CAM attractive ("basket of images")? }\end{array}$ \\
\hline $\begin{array}{l}\text { Transition initiatives: } \\
\text { strategies and programmes }\end{array}$ & $\begin{array}{l}\text { - How is the possible transition to CAM envisioned? What corresponding aims and } \\
\text { strategies are there? What investment programmes have been agreed? } \\
\text { - How have the strategies and implementations been formulated (e.g. as road maps)? }\end{array}$ \\
\hline
\end{tabular}


CAVs was conceived in the form of a step-by-step plan. The most important medium-term aim is to reclaim space in the inner city (until now used for parking spaces) in order to create e.g. more housing through densification. In no other region of the world have so many real and virtual kilometres been driven in automated transport than in California (US Senate Hearing 2018).

\section{LONDON AND METROPOLITAN REGION (UK)}

Drivers: The current challenges facing urban development in London are the rapidly growing population in the region, increasing traffic jams on the main transport routes, rising social inequality and the acute need to compensate for rapid urban growth by means of decentralization (GLA 2015). The widely shared expectation that the development and deployment of CAVs will bring technical and economic benefits is the most important driver of investments in the research and application of CAVs in the United Kingdom.

Innovation networks: In the UK, there are numerous university institutes, influential non-university research organizations and think tanks that contribute greatly to the local and national discourse and to the promotion and development of CAVs. The British Department for Transport (DfT) and Department for Business, Energy \& Industrial Strategy (BEIS) together launched the Centre for Connected and Autonomous Vehicles (CCAV) in 2017 (UK Parliament 2017). The CCAV is the single point of contact for the development of CAT in the UK.

Development narratives: The most important development narratives and strategies for the future of mobility and the visions for CAM embedded within that are concentrated on economic competitive advantages, on health and well-being, on social inclusion, on "good" growth and on the notion of a polycentric city (GLA 2017, NLA 2017, TfL 2017).

Transition initiatives: London's long-term urban development strategy is based on two pillars. There is a focus on the one hand on decentralized growth and on the other on citizens' health and well-being (TfL 2017). A detailed road map for the development of CAT in the UK was formulated after extensive public consultations (DfT 2015). In the course of this, a special process for selecting sponsorship projects to develop and test CAVs was implemented. Numerous projects have studied how citizens view and deal with CAM in everyday life.

\section{- GOTHENBURG (SWEDEN)}

Drivers: The challenges facing Gothenburg are a growing population, rising economic and social inequality, increasing freight traffic (the largest port in Scandinavia is in Gothenburg), the effects of climate change on nu- merous urban districts (rising sea level) and an expanding knowledge-based economy which needs new kinds of socio-economic communication spaces. The presence of a range of companies (like the Volvo Group) has raised expectations in the city that it can gain competitive advantages by investing in the research and development of CAVs.

Innovation networks: The cooperation and collaboration platform Drive Sweden is the most important organization to be set up in Sweden to publicly support the development of CAVs (Drive Sweden 2018). With so-called "Co-Creative Labs" (SAFER 2017), the urban planners in Gothenburg are attempting to involve the population in the joint development of a citizen-driven perspective for CAM.

Development narratives: The main urban development narrative in Gothenburg is the "Compact City" (City Planning Authority 2014). Its aim is on the one hand urban densification and on the other developing and strengthening Gothenburg as a hub in the knowledge-based economy. Awareness is being raised in the population for a change in urban mobility and transport ("A completely new type of mobility").

Transition initiatives: Gothenburg is intended to become a city of short distances ("closely-connected city"; Urban Transport Committee 2014). Drive Sweden sponsors various cooperative research and development projects like the deployment of self-driving shuttle buses that are suitable for a compact city. An interactive and evolving road map for the development of CAM in Sweden on the Drive Sweden website informs interested actors about the development status and possible stages of the transition to fully automated driving. A big step for the city of Gothenburg and its automotive and communication sectors was the construction of Asta Zero, a CAV testing ground of international significance.

\section{TOKYO AND METROPOLITAN REGION (JAPAN)}

Drivers: The challenges in Tokyo (and Japan as a whole) are a dramatically shrinking and ageing population, an acute shortage of labour and stagnant economic growth (Funabashi 2018, IPSS 2017). Furthermore, hosting the Olympic Games that were originally planned for 2020 was and is a driver for the rapid development of CAVs.

Innovation networks: With the SIP ("Cross-Ministerial Strategic Innovation Promotion Program") - and the support of the prime minister - the Council for Science, Technology and Innovation created a unique kind of horizontal, cross-departmental organizational structure (Amano/Uchimura 2016, 2018; SIP 2017). This started a process to overcome the compartmentalization of institutional "silos". A specific area of this programme, the SIP-ADUS (Automated Driving for Universal Ser- 
vices), enables both the coordination of research and development (SIP-ADUS for CAM) and the orchestration of the "Triple Helix" in Japan between government actors (cross-departmental), industry and research institutes (Amano/Uchimura 2016, 2018; SIP-ADUS 2016).

Development narratives: With "Mobility bringing everyone a smile" (Kuzumaki 2017), the city government wants above all to include seniors. In contrast, the two narratives "World's safest and smoothest road traffic system" (Prime Minister's Cabinet 2017) and "World's most advanced IT nation" are aimed at businesses. The road map "Society 5.0" refers to the current public discussion in Japan about the future of society in the age of digitalization, robots and artificial intelligence (FIRST 2018). In Japan, the safety aspect concerns the constantly growing threat of major earthquakes; for this reason, special safety systems have already been installed in public transport.

Transition initiatives: Tokyo's development up to 2020 was shaped by several action plans. The main idea was to equip the megalopolis of Tokyo with numerous compact city hubs (MLIT 2013, Tokyo Metropolitan Government 2016). The two most important social issues for which CAM is expected to provide solutions are firstly the ageing population and secondly the shrinking workforce. Most CAM projects currently aim to connect Tokyo with its suburbs and surrounding rural area (Prime Minister's Cabinet 2017). Under the coordinating aegis of the cross-departmental SIP-ADUS, Tokyo has produced the most detailed CAM road map of all the pioneering regions discussed here. It contains all the aims, strategies and concepts for the deployment of connected and automated vehicles, including a timetable for their implementation and roll-out in Japan by the year 2030. A unique feature of the strategy in Japan is the successive creation of a dynamic, nationwide, digital map of the streetscapes (Koyama 2015).

The ageing population and the accompanying dramatic reduction in the rural population are among the dominant issues in Japan. In the long-term vision "The Grand Design 2050" (MLIT 2013), a densification of smaller cities and towns in suburban and rural Japan is proposed (Funabashi 2018). Most CAM projects currently focus on these matters.

\section{- SINGAPORE}

Drivers: Urban challenges in Singapore are the acute shortage of land in combination with the growing population and their increasing demands for better mobility options, the construction and expansion of urban areas ("New Towns") and a lack of skilled workers (LTA 2013, 2018; Loo 2017; Human Resources 2018). Other drivers are improving global competitiveness and maintaining location quality.
Innovation networks: The cross-ministerial Committee on Autonomous Road Transport for Singapore (CARTS) was created as part of the city administration of Singapore to focus exclusively on testing and implementing CAVs and CAM in Singapore (Huiling/ Goh 2017, MOT 2017). The committee is accompanied by three working groups (cross-sector and transdisciplinary), which are responsible for drawing up medium- and long-term visions for CAM in Singapore and checking the parameters for possible applications (costs, regulatory framework, etc.).

Development narratives: The three most important development narratives are Singapore's all-encompassing digitalization strategy "Smart Nation", the vision of a city without cars "Car-lite City" (LTA 2018) and the model of a "Livable City" (CLC 2014, Smart Nation Singapore 2018). The innovation discourse in Singapore is shaped by the possible compatibility of new technologies with an identity-forming and "emotional" urbanism ("Can you love a smart city?"). In order to limit the number of authorized cars, since February 2018 new cars are only permitted in Singapore if they replace an existing car.

Transition initiatives: Compared with all the other pioneering regions, in Singapore CAVs enjoy the highest level of integration in urban development. The centralized government of the city state of Singapore has pursued the ideal of integrated planning for 50 years by means of various instruments of interinstitutional collaboration (URA 2016). On the basis of intensive cross-sector cooperation (including cooperation with investors), locations and use cases for CAVs can be planned and implemented in an appropriate and targeted manner. Two new high-density settlement areas ("New Towns"), which should be completed by 2024, are already designated for diverse location-specific applications of CAVs for both peak and off-peak times and for both daytime and night-time operation (see Fig. 4.5.3). In addition, intensive work is underway in Singapore on education formats and programmes to qualify and train workers in the field of CAM.

\section{CONCLUSION: “AUTOMATED AND CONNECTED MOBILITY FOLLOWS (INNOVATION) NARRATION"}

The results of the study suggest that despite the increase in safety, traffic efficiency, economic advantages or savings on parking spaces generally being the most frequently cited arguments for the deployment of CAVs in the city, the local designs and CAM strategies can in fact be surprisingly diverse. This diversity even reveals counternarratives to the current economic mainstream. The case studies show that technology is not deterministic for CAVs and CAM and that such strategies are the result of complex negotiation processes. It is also 

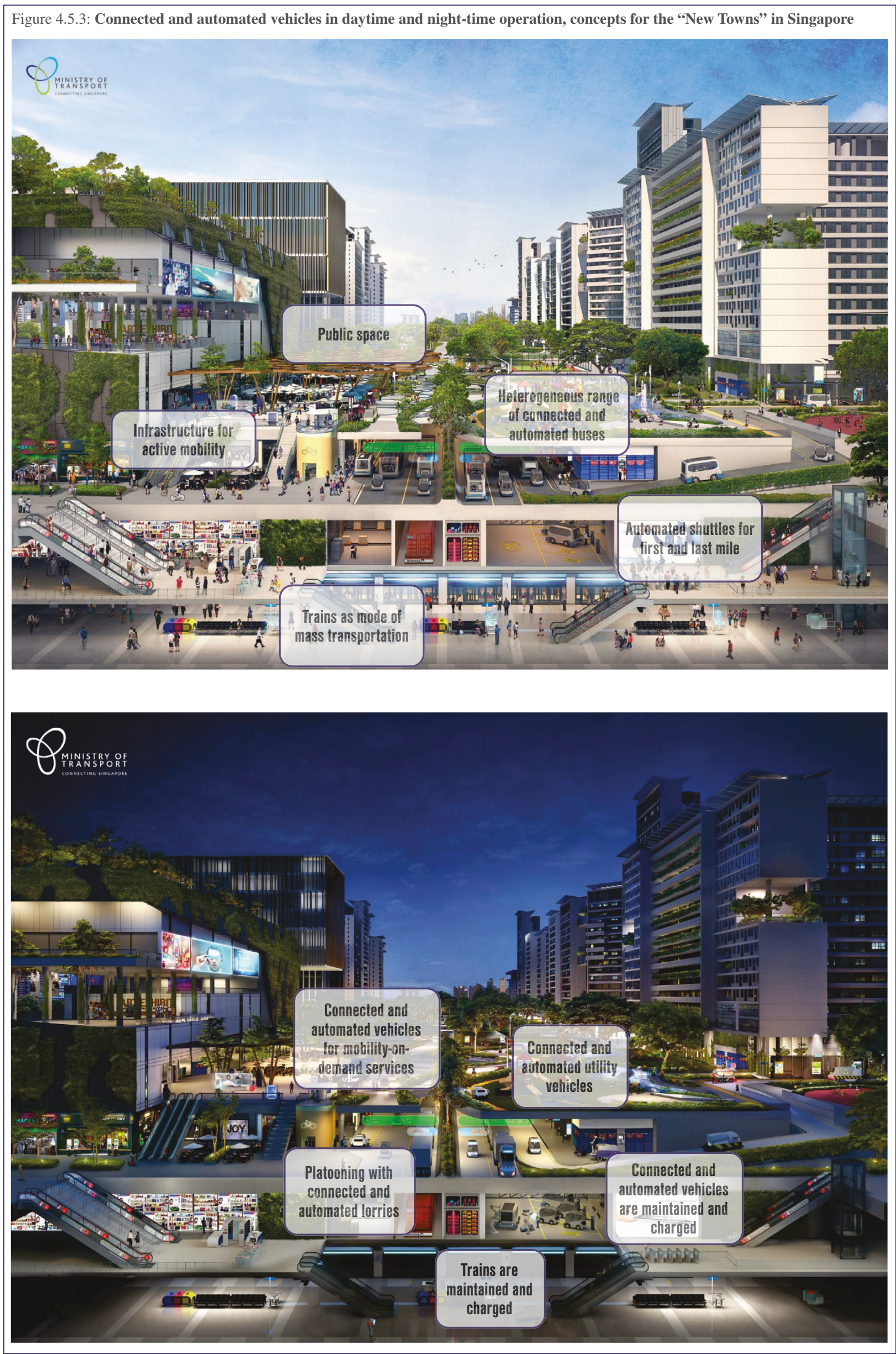
important to recognize that all cities are preparing for a system-wide transition period of several decades. However, most of them have identified specific urban spaces where they can implement CAVs of lower automation levels much earlier.

The four analytical categories (1) drivers, (2) innovation networks, (3) development narratives and (4) transition initiatives show in all five pioneering regions that the intensity and nature of the local innovation discourse is decisive for the complex processes involved in the transition to CAM-based solutions. It should also be noted that the introduction and distribution of CAVs is only a part of the digital transformation of all aspects of life ("fourth industrial revolution"). Considering the wide-ranging consequences of the digital transformation, the crucial issue for the deployment of CAVs is therefore not whether the city is ready for CAVs or whether CAVs are ready to be deployed in the city, but rather how the actors in the city lead a discussion themselves and in cooperation with others - about sustainable urban development in the digital age (co-production in networks). The real-world implementation of CAM then follows the narrative that was established in the discourse. 
4.6

\title{
NEGOTIATING A DOMINANT NARRATIVE ABOUT CONNECTED AND AUTOMATED MOBILITY IN EUROPE
}

\author{
Insight into the dissertation of Andrea Stickler
}

The role that automation will play in the transport system is not only defined by technological possibilities but is largely dependent on which discourses and narratives $^{1}$ about CAM become established in the public mindset. These visions of the future and hence the acceptance of CAVs are greatly influenced by the messages conveyed by various branches of the economy, the media, research, film or art and indeed politics (Diehl/ Diehl 2018, Manderscheid 2018, Berscheid 2014). However, the political discourse plays a unique role because it has taken an extremely controversial turn in recent years, is leading or has led to certain political actions and hence has a determining influence on the conditions of the technology's deployment (through circulating knowledge, test beds and examples of best practice, support schemes, regulations, etc.). For this reason, the question arises in what direction politics (actors, institutions, processes and issues) will move in the course of CAVs' introduction and what policy and planning framework will be defined that will ultimately affect future steering options. ${ }^{2}$

Although the hopes for technological innovations in transportation have been evident in the political discourse for many years (e.g. European Union 2011), the expectations of the positive effects of CAVs are relatively new. The transport ministries of the G7 states first published a declaration on the strategic promotion of CAM in 2015. At EU level, a consensus between the 28 transport ministries on the joint promotion of CAVs' introduction was formulated with the Declaration of Amsterdam in April 2016 and called on the European Commission to develop a European CAM strategy (European Commission 2016). In the context of this confidence around the implementation of connected and automated mobility and around the anticipated positive effects, certain narratives have developed about how CAVs should be deployed in Europe and the effect they will have.

In the area of transport policy, the political and discursive arena is currently characterized by competing ideas, interpretations of problems, and interests, as well as by the various stakeholders' different communication and power resources. What is considered verified knowledge about CAM is closely connected to questions of power, because co-determining the ability and assertiveness of a dominant narrative at political level differs enormously between the various stakeholders. Following the multiple-stream approach (Kingdon 1986), not only the power structure but also the perceived pressure to act and existing transport policies, solutions and infrastructures are relevant for setting political narratives and agendas in a specific time frame (see Fig. 4.6.1).

Figure 4.6.1: Narratives about connected and automated mobility

Perceived pressure to act

(due to technological development, international competition, politically perceived problems of automobility)

Power structure

(involved stakeholders and their decision-making power)
TIME FRAME

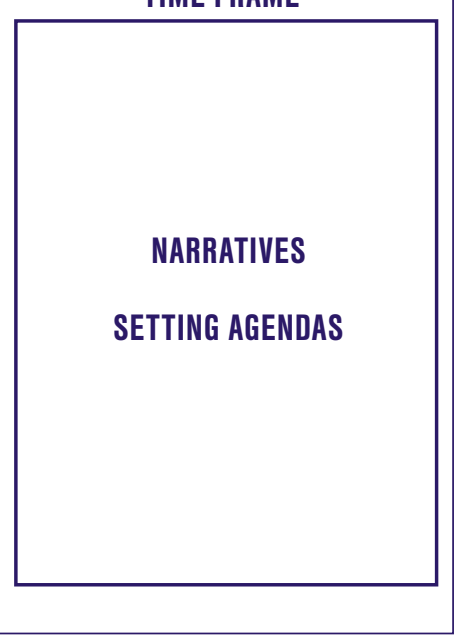

Existing transport policies, transport solutions and infrastructure 


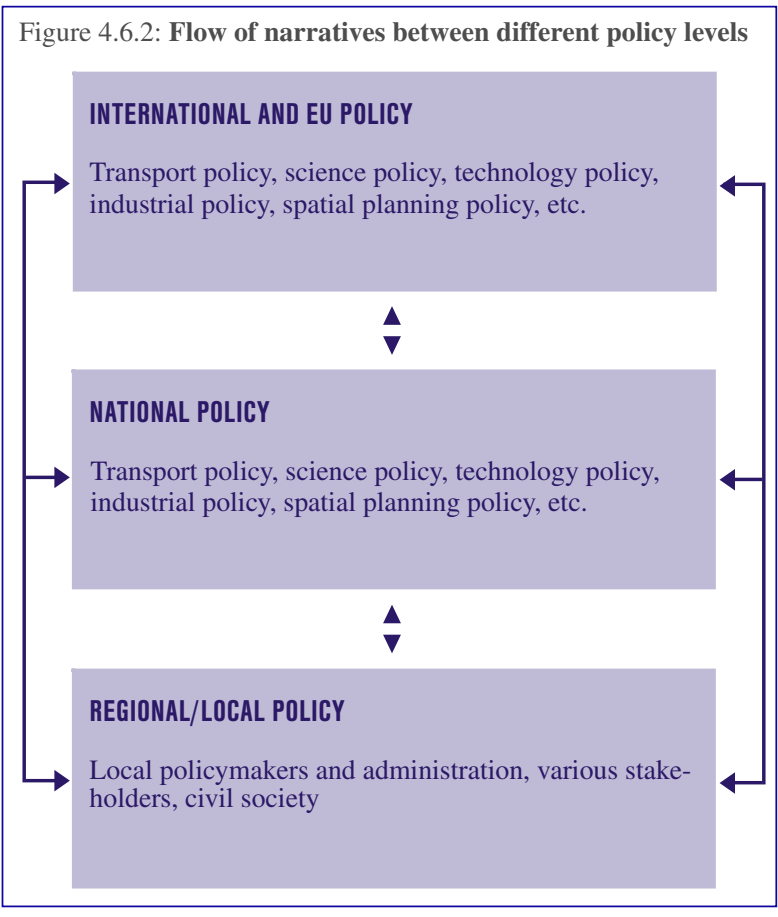

Source: AVENUE21

In political debates on CAM, undeniably relevant social challenges like climate protection, safety, the space consumed by cars and opportunities for people with restricted mobility are addressed and raised in public. However, design work is applied to these roblems in this context, for which specific technological solutions are then sought and developed in a cooperation between politics, various industries and research institutes. Hopes for the future and breaks with the past form a significant basis for the negotiation of a dominant narrative about CAM in this context. Predominantly with regard to the significance of automobility, the political discourse today is still sharply divided; even historically, there have been alternating phases of advocacy and criticism of automobility (Paterson 2007).
In the area of transport policy, the non-existent sustainability of current car traffic is largely undisputed, which is why the discourse on CAM within the EU increasingly revolves around environmental policy argumentation patterns. An ecological modernization (Bemmann et al. 2014) of cars should help to tap into the positive synergetic effects of vehicle automation, electrification and connectivity while simultaneously strengthening the competitiveness of the economy (and automotive industry) as well as improving European integration. As such, the narrative of a transformation in automobility with CAVs by means of an infrastructure prioritization of important transport routes within the EU (here in particular the C-ITS corridor from Rotterdam to Frankfurt and Vienna) is one that overwhelmingly has faith in technology and is growth oriented.

The EU's narrative on CAM, which is conveyed via policy programmes, political panels, events and the media, is becoming the new way to think and act in various areas and institutions (which is why the flow of narratives between different policy levels and policy fields should be considered, see Fig. 4.6.2).

Narratives at EU level contrast with other (inter)national notions of CAM, exert pressure on various political levels and are partly adopted and "translated" by national or local institutions (Clarke et al. 2015). This translation allows an entirely new negotiation of the issue, with new tensions, risks and opportunities. Certain aspects might be emphasized or ignored, and unexpected effects may emerge as a result of path dependencies, lock-in effects, challenges and tensions (see Fig. 4.6.3). For this reason, it is necessary to include specific spatial circumstances in considerations in order to understand the relationships between the political narratives and certain policy and planning actions (Jäger 2015: 112-113). Only by doing so does it become clear that although political discourses and narratives will have an impact on the

Figure 4.6.3: Interaction of political narratives, practices and social reality

Path dependencies, lock-in effects, contestations, tensions
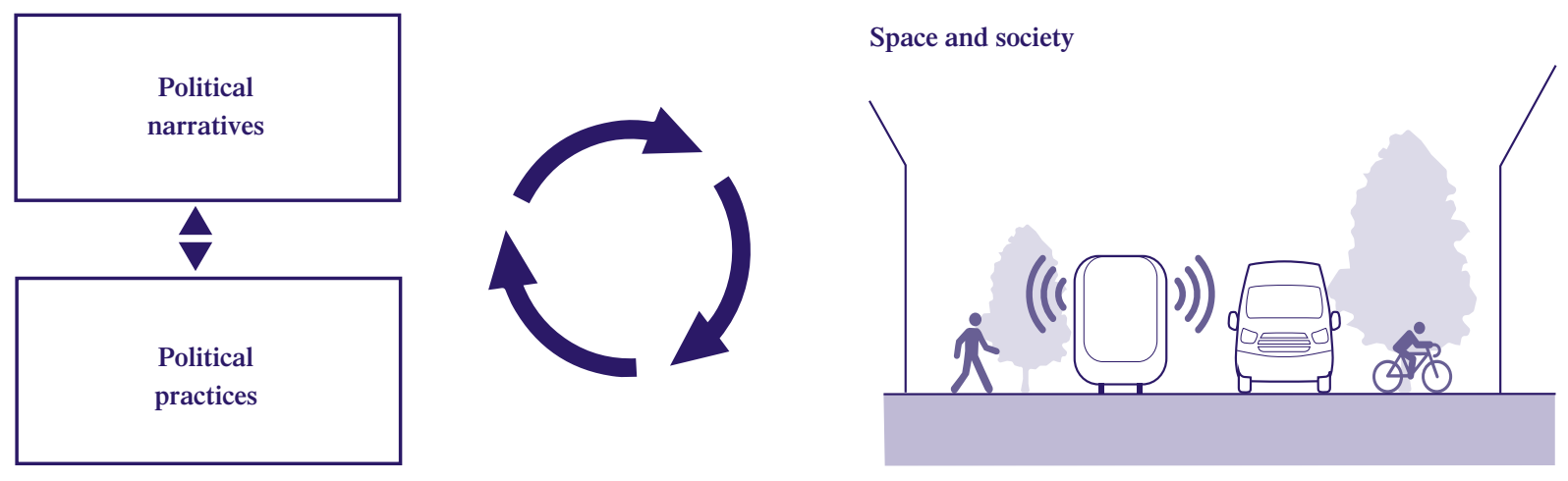

Source: AVENUE21 
new transportation revolution, they will not dictate the revolution because the transformation of automobility is embedded in a complex social and politico-economic nexus that has evolved over time (Urry 2004, Paterson 2007). Nevertheless, political discourses can contribute greatly to the new transportation revolution as they are linked with certain discourse practices that can indeed have an influence on structure and space.

The technical and growth-oriented notion of CAM within the EU is already being called into question. Particularly at local/municipal level, the negative effects of automobility and the limits to its growth are tangible, which is why further traffic growth with CAVs is the subject of very contentious debate. Doubts can also be raised about a growth-oriented transformation narrative from an empirical and theoretical perspective: statistics point to a considerable increase in road traffic (Umweltbundesamt 2018, Statistics Austria 2018), which will soon reach its (ecological) limits. Social processes like individualization, flexibilization and social acceleration (Rosa 2013, Honneth 2016) as well as the dynamics of the global economic system (Boltanski/ Chiapello 2001, Schwedes 2017) tend to thwart rather than encourage environmentally friendly mobility at both a cultural and structural level. In light of this trend towards increasing traffic and a growth-oriented narrative around CAT, especially in cities many adverse effects of automobility (use of space, negative impact on pedestrian and bicycle traffic, sound pollution, etc.) could be exacerbated or maintained.

Despite this, in some discourses the potential of a radical transformation with CAVs is also recognized, because progress in the connection and automation of vehicle technology may change not only the car as a piece of technical equipment, but also the car's significance as a private commodity and ultimately how and why individuals are mobile (Kellerman 2018, Canzler/Knie 2016). However, these culture- and growth-critical discourses are often neglected in political debates at European level. To increase the politicization of CAM, more debate would be necessary between predominant and alternative narratives. Yet this would require the political level to think beyond an ecological modernization of the car, to discuss opposing visions of the future with CAVs and to hold more talks in the sociopolitical arena about the various possibilities for implementing CAVs.

In summary, it can be stated that especially due to the competing interests and interpretations of problems in modern-day transport policy, current political narratives around CAM should be critically challenged, because:

In the EU, a certain narrative is evolving between actors' conflicting priorities regarding how CAVs should best be deployed. This is leading to altered legal frameworks and funding strategies as political practices that will have a considerable impact on the future deployment of CAVs.

- The EU's narratives and political practices acquire a different meaning at local level, where they are being called into question and renegotiated. This negotiation process should be strengthened intentionally and opened up to various interest groups.

- Research can help expose the prevailing power relations that shape the discourse around CAM and serve as "early warning systems" for potentially unexpected consequences.

1 The term "narrative" is interpreted here as the communicated and staged narrative or myth around CAVs and CAM. These narratives refer to control systems that give rise to certain forms of knowledge and meanings and hence structure the public and/or political discourse (Viehöver 2001: 177-178).

2 Specifically, this addresses the question of how CAM is uttered as an object of knowledge by various stakeholders. We take a discourse theory approach and refer methodically to discourse theories such as those of Keller (2004) and Jäger (2015). 
4.7

\section{PLANNING APPROACHES THAT PROACTIVELY SHAPE URBAN FUTURES WITH CONNECTED AND AUTOMATED VEHICLES}

Insight into the dissertation of Emilia Bruck

Even though connected and automated mobility is increasingly being discussed in light of existing urban development aims (Heinrichs et al. 2019), suitable planning approaches to steer the urban integration of CAVs have not yet been adequately addressed (Guerra 2016, Fraedrich et al. 2018). With few exceptions (Chap. 4.5), urban planners have not had sufficient knowledge of the consequences of CAM on urban planning and settlement structure to be able to establish development priorities and manage investments appropriately (Fraedrich et al. 2018).

There are uncertainties regarding impacts on infrastructure, urban space and society because it has not yet been possible to analyse the local benefits of CAVs in terms of environmentally and city-friendly mobility. However, when one considers that the nature and extent of CAM's possible effects will in part only be identifiable after its implementation (Guerra 2016), urban planners need to reflectively engage and be actively involved in shaping that implementation in good time in order to act as a driving force and represent the city region's issues concerning technology development, science funding and policy. Assuming that CAVs will not be deployed spatially and socially from the outset, but only (co-)generated by public and political negotiation (Guthrie/Dutton 1992, see also Chap. 4.6), urban planners also bear creative responsibility, as the spatial objectives set during the formative phase will shape and possibly have a lasting impact on the further development of the technology. Now the urgent question presents itself as to at what point specific planning measures should be adopted and what shape the necessary vision and strategy-finding process should take.

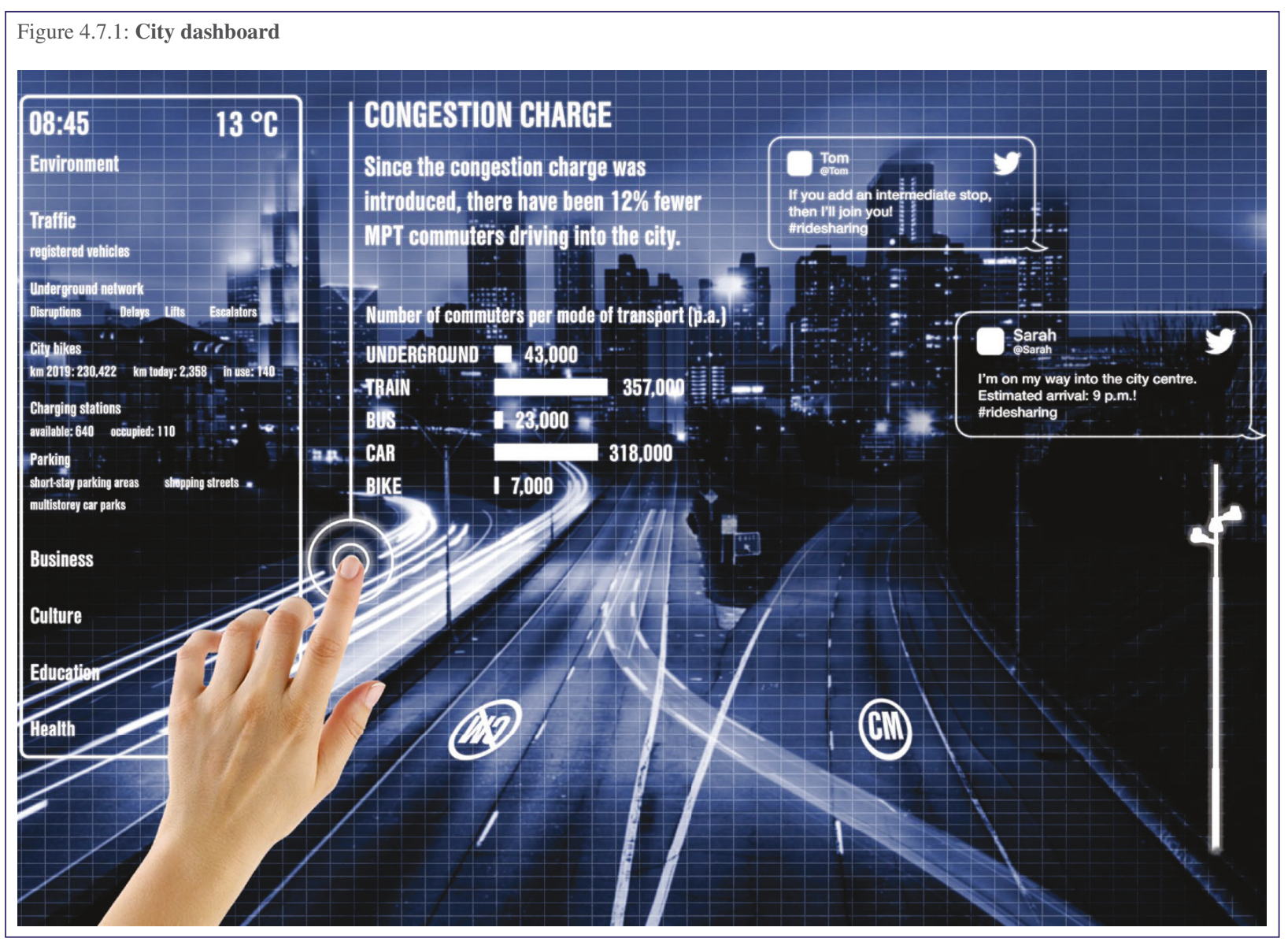




\subsubsection{TECHNOLOGICAL CHANGE AS A CHALLENGE FOR URBAN PLANNING}

The introduction of CAVs fits into a process of upgrading information technology in numerous European (London, Vienna, Amsterdam, Barcelona, Dublin, etc.) and international (New York, Singapore, Hong Kong, Pune, etc.) cities. Over the past two decades, strategy papers have been written on this topic with the "smart city" as their leitmotif; although they differ in their specific objectives, development processes and implementation strategies, they largely aim to adapt technological and economic trends to local development requirements (Townsend/Lorimer 2015). Given limited infrastructure capacity, fiscal austerity, the climate crisis and ongoing urbanization trends, it is hoped that smart infrastructure development will guarantee urban resilience and sustainability (White 2016). With the aspiration to monitor, manage and steer urban processes in real time (Kitchin 2015), a technology and management-oriented planning approach is taking hold which is based on the conviction that with "better" data and "better" models, uncertainties and risks will be considerably reduced if not entirely eliminated (Hillier 2016: 300). The prediction and control of events within infrastructure networks or public spaces (see Fig. 4.7.1) is at the heart of this promise (Picon 2015). Hence the idealized smart city developments like Songdo (South Korea), Masdar (Abu Dhabi) or Sidewalk Toronto (Canada) are ultimately urban planning exceptions that are intended to make it possible to demonstrate sensory connection and prognostic data analysis away from the chaotic reality of a city, with data being gathered on the defining category of urban transformation (Halpern et al. 2013).

Yet the introduction of technological innovations for the purposes of energy supply, transport systems or communication services and the associated adaptation of cities also leads to unexpected side effects related to digital and automated processes (Townsend 2013, Kitchin/Dodge 2017). In addition to the promised advantages of convenience, safety and economic growth, the recurrence of urban problem areas and risks (emergence of new inequalities, security and criminality risks as well as pollution) can hardly be avoided (Kitchin/ Dodge 2017). The resulting issues consist less in the use of technological innovations than in the failure to adequately consider urban diversity and to reconcile the benefits with the social, cultural and spatial characteristics of an urban context and hence to maintain a historical perspective (Hajer 2014, Picon 2015). In view of the increasing service and mobility provision, cities run the risk of letting the discourse around local conditions for a liveable city in the age of digital transformation fall victim to an overhasty implementation of technological solutions (Hajer 2014: 16).
In the specific case of CAM, it should be considered that local path dependencies in the form of mobility cultures, settlement structures, business connections and established planning concepts are an obstacle to the desired optimization effects. The complexity of these historical interdependencies tends to reproduce a "car system" (Urry 2004: 27) and hence a "car city" whose infrastructure improvements paradoxically merely delay problems or cause more rebound effects (Sonnberger/ Gross 2018, Schneidewind/Scheck 2013). In order to change existing mobility and consumption practices in line with a sustainable transportation revolution (see Chaps. 3.1, 3.2), it is instead necessary to consider CAM in combination with social innovations. As technological artefacts always go hand in hand with a redesigned social order, social innovation, which can be understood as a social change process, is closely connected to technological artefacts (Braun-Thürmann 2005). On the one hand, this means that the deployment of CAVs cannot be understood as a simple solution to contemporary transport and planning problems, but must be critically contemplated in relation to the city's structure and society (Guerra 2016). On the other hand, it is essential that local planning strategies understand uncertainties as a natural part of the process and see unexpected developments as an opportunity for something new. While pilot projects on CAM should be tested both spatially and socially as soon as possible, they should be accompanied by a public discussion and collective learning process. In order to answer the question of what a long-term vision of urban coexistence with CAVs would look like, various directions of development must first be analysed and a discussion must be held around what is and is not desired.

\subsubsection{RELEVANCE OF REFLEXIVE PLANNING APPROACHES IN LIGHT OF NEW MOBILITY TECHNOL- OGIES}

Given the uncertainties and unpredictable developments that generally go hand in hand with innovation and transformation processes, flexible, explorative and reflexive approaches in planning theory and practice are gaining attention (Balducci et al. 2011, Roorda et al. 2014, Freudendal/Kesselring 2016, Bertolini 2017, Hopkins/ Schwanen 2018). For example, the understanding of "adaptive" or even "evolutionary" planning is based on an incremental trial of innovations and loose regulations in order to ensure urban resilience, i.e. the ability to regenerate and self-organize in a crisis, when faced with global challenges (Bertolini 2007, Rauws 2017). In light of "robust planning goals" (Bertolini 2017: 147), which despite uncertainties can be deemed desirable for various futures, the real-world potential of technological innovations must first be tested by means of exploratory acts. Variations and selection processes must be taken into consideration both in the conception phase and in 
later planning and development stages in order to learn from experiences and be able to make changes (Bertolini 2017: 156).

In the discourse around "reflexive governance", two main readings of the concept are differentiated (Voß et al. 2006). In the first instance, reflexivity is understood as the state of governance in a modern world, which is constantly being confronted with the unintended consequences of earlier actions, indeed with risks and limits (Voß et al. 2006, Schwarz 2014). ${ }^{1}$ A second reading concerns new strategies, processes and institutions which are initiated by self-confrontation ( $\mathrm{Voß} /$ Kemp 2006). The solution and planning approaches of modernity, which are based on scientific certainty and ultimacy, are replaced by discourse in a "reflexive modernity" (Schwarz 2014: 209). According to Stirling (2006: 260), reflexive strategies rest on the plurality and the conditionalities that underlie both scientific findings and technological potentials. Taking account of longterm systemic consequences and developing alternative strategies therefore requires a variety of perspectives and an expanded knowledge base (Stirling 2006: 258). Principles like non-finality, experimentation, fault tolerance, risk intelligence and acting in uncertainty (Voß et al. 2006, Heidbrink 2007, Schwarz 2014) are taking on greater significance, as is the conception of long-term strategies that create the framework for short-term, exploratory actions and enable cross-project learning (Lissandrello/Grin 2011). Reflexive strategies are relevant for planning in the sense of both concomitant monitoring and process design, for example in the form of open dialogues to develop visions of the future or exploratory urban interventions. The alternative practices necessary for transformation pathways require not least reflection on the respective structural conditions (Grin 2006, Lissandrello/Grin 2011).

Yet it is not only within the planning discourse that urban interventions and experimental spaces have gained attention in recent decades (Heyen et al. 2018). Especially in the context of sustainability and transformation research, real-world trials have increasingly been encouraged for the purposes of applied research and analysing change processes (Schneidewind/Scheck 2013). In these trials, cities or city districts serve as geographically, temporally and institutionally delimited reference areas within which scientific and practical knowledge can be integrated by initiating and enabling social and technological change processes (Schneidewind/Scheck 2013: 240). Alongside the real-world laboratories frequently mentioned in the transformation debate in the German-speaking world, a range of international research approaches should be noted, including (sustainable or urban) living labs, (urban) transition labs and (sustainable) niche experiments (Schäpke et al. 2017). ${ }^{2}$ As no standardized methodical practice has yet been established in the research community, real-world laboratory approaches in the German-speaking world have varied in terms of individual characteristics like the understanding of transformative research, the carrying out of real-world experiments, transdisciplinary types of cooperation and further contributions to social change processes by means of sharing and conveying generated knowledge (Schäpke et al. 2017).

If urban real-world laboratories are understood as a transdisciplinary framework, they can serve to correlate various real-world experiments, to define a shared objective and to enable overarching knowledge sharing and reflection processes (Beecroft et al. 2018: 77). In accordance with transformative research, the research, practice and educational aims of a real-world laboratory, of the individual projects and of the involved actors must be coordinated. Even if collaboration on an equal footing is aspired to, it is difficult to avoid conflicts of interest and objective as well as epistemic confrontations (Dusseldorp 2017, Singer-Brodowski et al. 2018). Some real-world experiments can be categorized as being methodically between pure knowledge application and knowledge creation (Schneidewind/Scheck 2013: 241), with situation-specific settings in particular, similar to transition experiments, aiming to contextualize technological or ecological possibilities and to socially empower radical alternatives. Through continuous (self-) reflection and evaluation, an experimental-reflexive research style (Beecroft et al. 2018: 78) can contribute to processes being adapted to new or unexpected conditions and to the real-world laboratory as a whole being able to learn (Flander et al. 2014).

In light of technological innovations like CAVs, realworld laboratories constitute a relevant instrument for urban planning in terms of transformation research in order to launch a collective learning process with the involvement of civil society. Especially issues like changing mobility behaviours, the accessibility of and barriers to new mobility services and alterations to urban planning are suited to such laboratory situations. The opportunities for and limits to generating local knowledge or even to initiating change will be determined by the integration of various target dimensions and the prioritization of research principles. For urban development, it remains imperative to constantly ensure the social legitimacy of the objectives, the process design and the results (Schäpke et al. 2017).

\subsubsection{INCLUDE CONNECTED AND AUTOMATED VEHICLES IN PLANNING DESPITE UNCERTAINTIES?}

With regard to the formative phase of CAM and its urban deployment, reflexive, explorative and adaptive processes can be significant in several ways as part of strategic planning. First, they can counter a purely technology-driven rationality that strives to minimize the complexity and uncertainties and maximize risk control with the aid of 
fast, standardized solutions. By contrast, it is important to pursue planning approaches that focus on the conditions and necessary capacities so that urban development can take place under various future conditions (Rauws 2017). In the sense of an "adaptive" or "incremental" planning approach (Rauws 2017: 36), a strategic framework and an orientation aid can be created with development guidelines that preserve context-specific flexibility without stipulating specific spatial function designs or coalitions of actors in advance. Given the new landscape of actors and IT companies' increasing advances in knowledge, public competence development and knowledge creation are particularly necessary. In addition to conveying multisector interests, it is up to urban planning to accommodate the complexity of urban transformation processes and pursue measures that may be conducive to a variety of scenarios and urban lifestyles (Guerra/Morris 2018). Here it is less a matter of finding spatial or technological solutions than including spaces of possibility in urban planning that are open for future developments, i.e. strengthening the spatial and social ability to adapt and react.

Furthermore, the approaches, structures and systems should be contemplated that produced and preserve a car system in order to counteract its perpetuation with CAVs. To achieve this, proactive planning approaches are necessary through which contentions, confrontations and changes of perspective are voiced and made possible amongst planners, policymakers, scientists, businesspeople and civil society. In open dialogues and transdisciplinary projects whose aim is the long-term transformation of social practices, actors can be encouraged to discuss existing challenges and a necessary adaptation in behaviour. With the aid of reflexive strategies, problematic situations can be brought to light, expectations of the future specified and structural constraints contemplated in light of existing routines (Lissandrello/Grin 2011). Such processes serve to encourage not merely communication between the actors, but also the integration of various perspectives in order to develop a shared view of reality, even if it includes various understandings of the problem, aims and strategies at first (Voß et al. 2006). The plurality of views and the collective creation of knowledge come to the fore of the collaboration (Voß/Kemp 2006). When calling attention to local development possibilities and synergies between the existing and the new, it is necessary to realign stakeholders' imaginations and identify alternative visions of the future for a city region or district. Ideally, previous understandings of urban mobility will change, while individual demands will approximate alternative future pathways (Lissandrello/Grin 2011: 244). In this way, reflexivity in planning, which also includes questioning the role and the underlying convictions of planners themselves (Beecroft et al. 2018: 92), can trigger a change process through productive confrontations (Lissandrello/Grin 2011: 226). The context for critical explorations of the future creates a framework for transformative practices that go beyond communicative and strategic planning principles.

Finally, the suitability of new mobility services for a specific spatial and social context can be checked or voted on using explorative planning approaches. To date, trial runs of highly automated vehicles (Level 4) have taken place in controlled orientation and experimentation contexts in

Figure 4.7.2: Integration of urban experimentation spaces with connected and automated vehicles in the typology of experiments

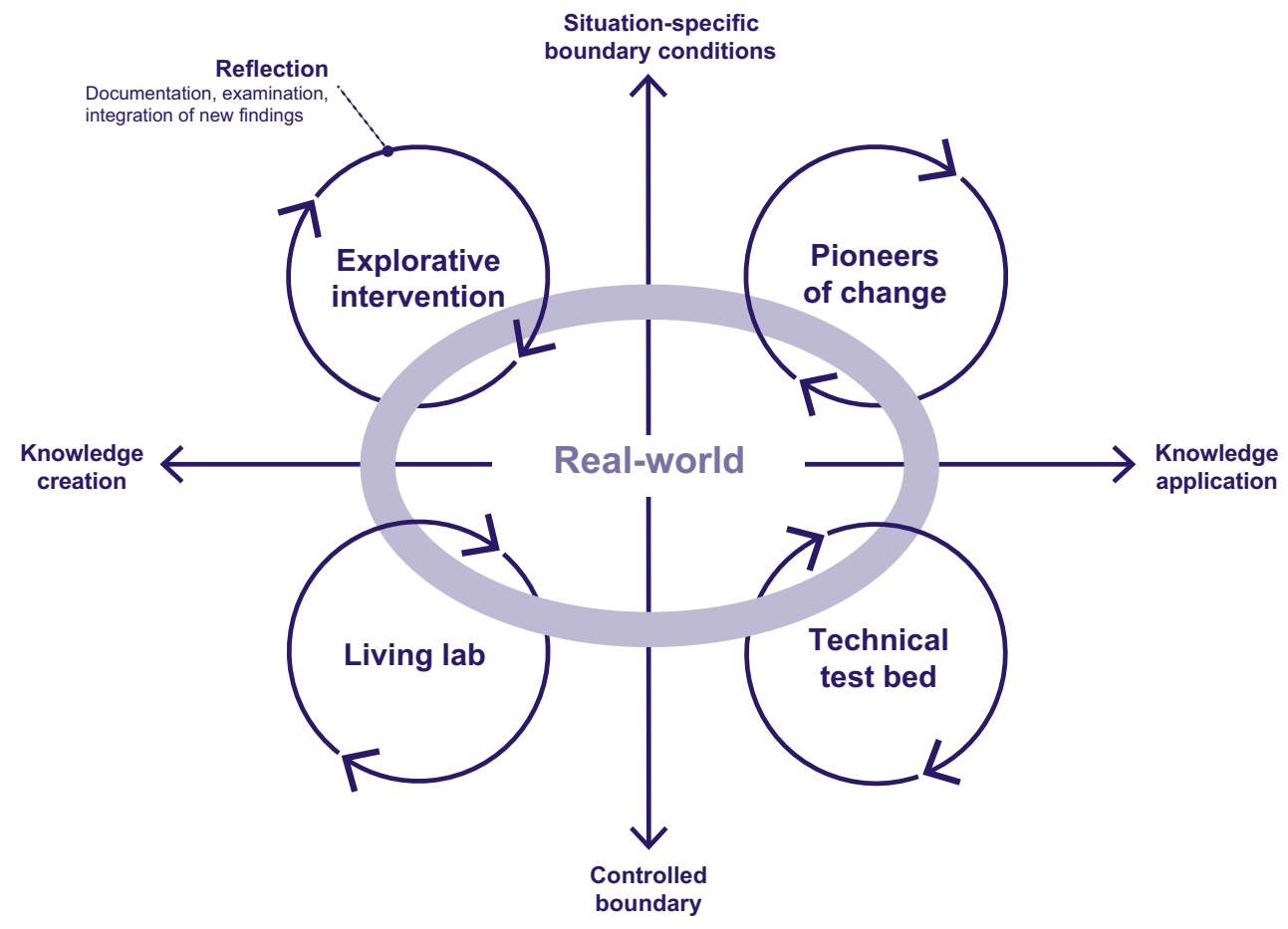


order to acquire transferrable knowledge for the purpose of technology development (see Chap. 4.1). Thus, the realworld trials of CAM can be characterized as being between controlled test beds, i.e. demonstration sites, and living labs, i.e. real-world tests with the involvement of users (see Fig. 4.7.2). Aspects like changes in mobility habits, interactions in the urban space and the diverse user needs of target groups like people with limited mobility have hardly been taken into consideration in connection with CAM. From the point of view of the city and urban planning, it must therefore be established what insights can be gained from the studies conducted thus far and to what extent future trials can be methodically expanded and co-created.

Moreover, explorative trial actions in the form of shortterm urban interventions or real-world urban laboratories can help to answer transformation-related questions in an exemplary way and gain location-specific experience. However, the requirement should be to pursue aims that are socially legitimized, ethically well founded and for the common good (Defila/Di Giulio 2018). From a scientific perspective, specific knowledge of the system, objective, transformation and process should be surveyed locally, the social relevance of the respective research questions should be tested by involving practice-oriented actors and the focus of individual real-world experiments should be chosen collaboratively (Beecroft et al. 2018: 80).

In addition, those local actors should be taken into consideration who concern themselves with the impact of new mobility services on public space, working conditions, communities, the climate, education, accessibility and affordability. Triggering alternative mobility practices and different means of use would make it possible to acquire practical knowledge about unintended consequences, the transferability of results and the effects and requirements of forms of cooperation and empowerment (Beecroft et al. 2018: 81). If issues and transformation aims are locally grounded and self-organized groups are empowered to propose their own ideas for solving problems, then initiatives can arise that generate cultural, social and spatial added value and bring about cultural change as "change agents" or pioneers of change (WBGU 2011: 256). This would require not only an openness to sociocultural particularities and collaboration on equal terms, but also the possibility for local actors to participate beyond the time frame of mere project stages. Systematic reflection on the collaboration and the results can ultimately serve various education processes, such as the ability to learn and adapt within real-world laboratories or the formulation of transformation pathways as social learning processes in the broader sense (Schneidewind/Singer-Brodowski 2015). Creatively reconfiguring the present and experimenting with the ability to change make reflexive and explorative processes valuable niches in which the limits of what is possible are retested and urban diversity as a quality is maintained (Abbott 2012).
1 This refers to "reflexive modernity" according to Beck (1986) and others (Beck et al. 2003), meaning the fundamental transformation of a modern society and its political systems. In contrast to the views of a postmodern era, with the concept of reflexive modernity the authors assume a restructuring and reconceptualization of social conditions and historical ruptures. According to Latour (2003), reflexivity does not mean the increase in controllability and consciousness, but rather the awareness that complete controllability is effectively impossible.

2 According to Schäpke et al. (2017: 49), the three approaches should be differentiated with regard to methodical technique, focus and underlying theories: (1) living labs aim at marketable, standardized products and services as well as generalizable findings - and hence they limit participation and strive for controlled experiments and settings; (2) transition experiments target evolutionary forces, the empowerment of pioneers and reinforcement of alternatives - as well as the orchestration of experiments and specific, real-world change; consequently, the approach focuses on strong forms of participation and empowering mechanisms of disseminating alternatives through learning; (3) niche experiments contribute to the generation of reflexive knowledge through their eschewal of conducting their own experiments; depending on the projects and processes analysed, this is highly contextualized or more generalizable. 
Open Access This chapter is licensed under the terms of the Creative Commons Attribution 4.0 International License (http://creativecommons.org/licenses/by/4.0/) which permits use, sharing, adaptation, distribution and reproduction in any medium or format, as long as you give appropriate credit to the original author(s) and the source, provide a link to the Creative Commons licence and indicate if changes were made.

The images or other third-party material in this chapter are included in the chapter's Creative Commons licence, unless indicated otherwise in a credit line to the material. If material is not included in the chapter's Creative Commons licence and your intended use is not permitted by statutory regulation or exceeds the permitted use, you will need to obtain permission directly from the copyright holder.

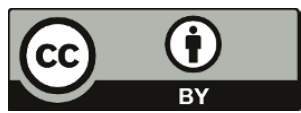

